Prepared in cooperation with the U.S. Fish and Wildlife Service

Long-Term Effects of Wildffire on Greater Sage-GrouseIntegrating Population and Ecosystem Concepts for Management in the Great Basin

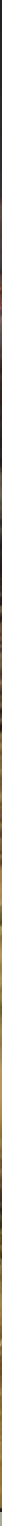

Open-File Report 2015-1165

U.S. Department of the Interior

U.S. Geological Survey 
Cover:

Top photograph: Sagebrush burning at Hart Mountain National Antelope Refuge in association with a management project located 65 miles northeast of Lakeview, Oregon. Photograph by Scott Shaff, U.S. Geological Survey, October 18, 2006.

Bottom photograph: Cheatgrass invasion following wildfire in Central Nevada north of Austin. Photograph by Caitlin Bowman, U.S. Geological Survey, August 2015.

Inset: Photograph of a male greater sage-grouse performing a courtship display on a lek in northeastern Nevada, 2012. Photograph courtesy of Tatiana Gettleman. 


\section{Long-Term Effects of Wildfire on Greater Sage-Grouse- Integrating Population and Ecosystem Concepts for Management in the Great Basin}

By Peter S. Coates, Mark A. Ricca, Brian G. Prochazka, Kevin E. Doherty, Matthew L. Brooks, and Michael L. Casazza

Prepared in cooperation with the U.S. Fish and Wildlife Service

Open-File Report 2015-1165

U.S. Department of the Interior

U.S. Geological Survey 


\section{U.S. Department of the Interior \\ SALLY JEWELL, Secretary}

\section{U.S. Geological Survey \\ Suzette M. Kimball, Acting Director}

U.S. Geological Survey, Reston, Virginia: 2015

For more information on the USGS—-the Federal source for science about the Earth, its natural and living resources, natural hazards, and the environment-visit http://www.usgs.gov or call 1-888-ASK-USGS

For an overview of USGS information products, including maps, imagery, and publications, visit http://www.usgs.gov/pubprod

Any use of trade, firm, or product names is for descriptive purposes only and does not imply endorsement by the U.S. Government.

Although this information product, for the most part, is in the public domain, it also may contain copyrighted materials as noted in the text. Permission to reproduce copyrighted items must be secured from the copyright owner.

The findings and conclusions in this article are those of the author(s) and do not necessarily represent the views of the U.S. Fish and Wildlife Service.

Suggested citation:

Coates, P.S., Ricca, M.A., Prochazka, B.G., Doherty, K.E., Brooks, M.L., and Casazza, M.L., 2015, Long-term effects of wildfire on greater sage-grouse-Integrating population and ecosystem concepts for management in the Great Basin: U.S. Geological Survey Open-File Report 2015-1165, 42 p., http://dx.doi.org/10.3133/ofr20151165.

ISSN 2331-1258 (online) 


\section{Preface}

This study was conducted to provide timely scientific information regarding the effects of wildfire on greater sage-grouse (Centrocercus urophasianus) demography within the Great Basin over the last 30 years. Findings are provided to fill a prominent information gap in the threat assessment for greater sage-grouse populations as part of the listing decision process by the U.S. Fish and Wildlife Service under the Endangered Species Act of 1973. The primary purpose of the current report is to present a Bayesian approach to estimate the effects of wildfire on greater sage-grouse population rate of change while accounting for influential interactions with climatic conditions (that is, precipitation). We also used the derived parameters (medians from posterior probability distributions) of those relationships to estimate population size in 2044 relative to measured abundance in 2013-2014. The findings of this report were based on multiple long-term datasets, including 30 years (1984 to 2013) of wildfire history, and spatially explicit data of climatic conditions, soil moisture and temperature, and lek (breeding grounds) counts that were restricted to the 30-year analysis period. A complementary report using a wildfire dataset that spans the geographic range of greater sage-grouse was concurrently published with this report. The concurrent study focused on recent spatiotemporal patterns of fire regime characteristics during the same 30 -year time period with implications for conservation and management of the greater sage-grouse (Brooks and others, 2015). 


\section{Acknowledgments}

We greatly appreciate the cooperation of all State fish and wildlife agencies in the Great Basin who graciously provided lek count data under the auspices of the Western Association of Fish and Wildlife Agencies (WAFWA). These agencies included Idaho Department of Fish and Game, Nevada Department of Wildlife, Oregon Department of Fish and Wildlife, California Department of Fish and Wildlife, and Utah Division of Wildlife Resources. We extend particular gratitude to T. Remington (WAFWA), who compiled and diligently executed quality assurance and quality control for all lek data across agencies. We thank the WAFWA Wildfire and Invasives Work Group, specifically K. Mayer, J. Chambers, D. Pyke, D. Havlina, S. Espinosa, L. Niell, J. Maestas, T. Koch, and T. Hopkins for helpful suggestions on improving this presentation and analysis. We also are grateful to S. Campbell (NRCS) for providing soil moisture and temperature data. Reviews of previous manuscript drafts by B. Fedy (University of Waterloo), J. Dinkins (University of Wyoming), J. Yee (U.S. Geological Survey), and D. Delehanty were particularly helpful. B. Halstead and J. Yee (U.S. Geological Survey) provided expert statistical advice, and downscaled PRISM precipitation data were graciously provided by P. Flint and L. Flint (U.S. Geological Survey). Expert GIS analyses, data management, and problem solving were provided by T. Kroeger and K. Mauch (U.S. Geological Survey). 


\section{Contents}

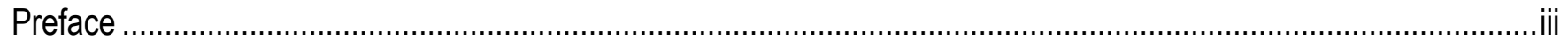

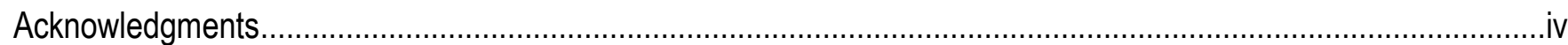

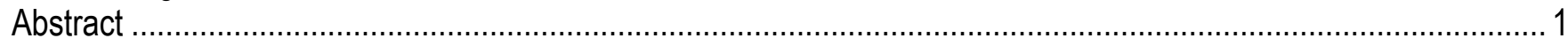

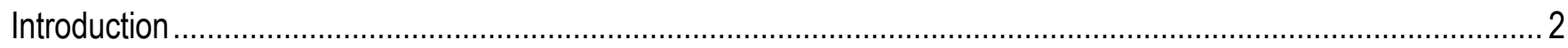

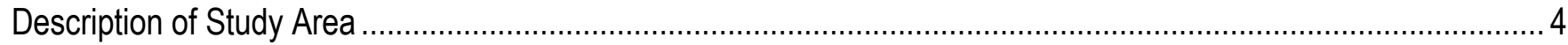

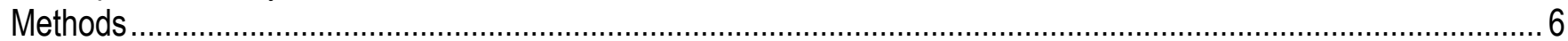

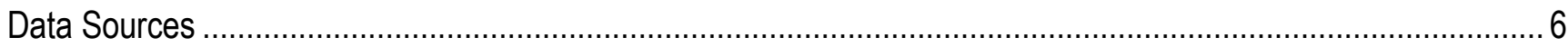

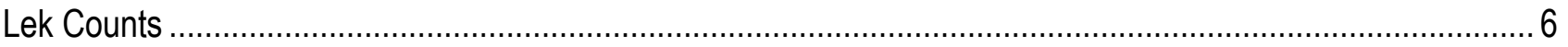

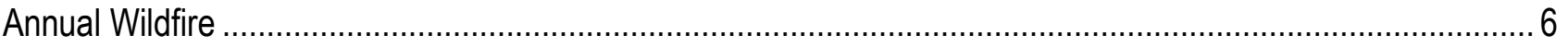

Precipitation

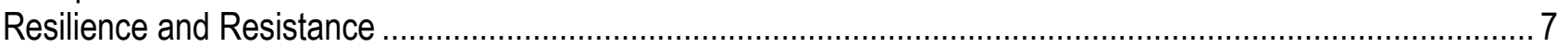

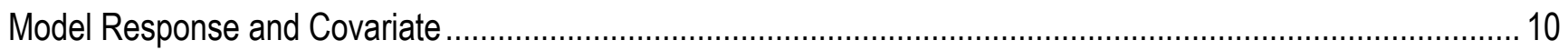

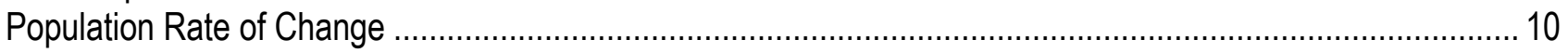

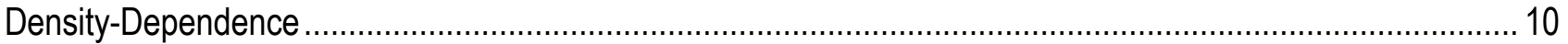

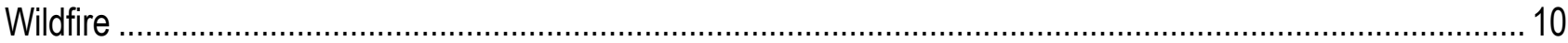

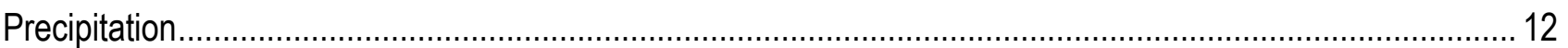

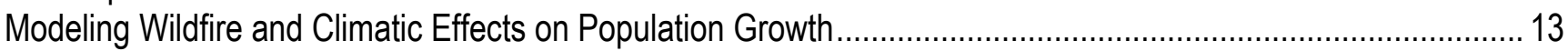

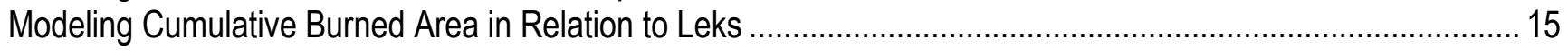

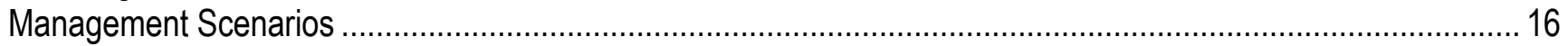

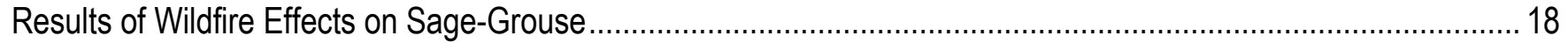

General 30-Year Wildfire Patterns across the Great Basin ........................................................................ 18

Wildfire and Precipitation Effects on Annual Population Rate of Change......................................................... 18

Patterns of Cumulative Burned Area and Recovery Near Leks................................................................... 28

30-Year Predictions of Cumulative Burned Area and Sage-Grouse Population Persistence ................................. 28

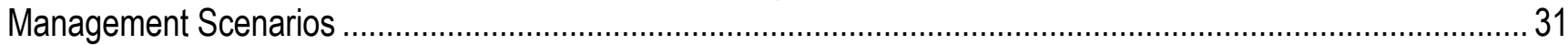

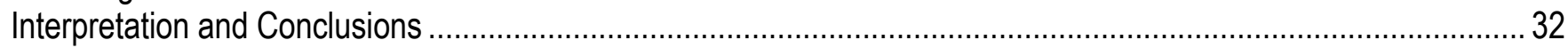

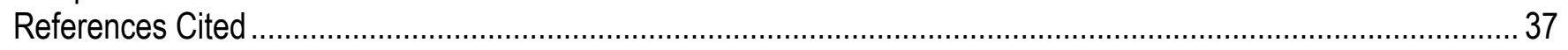

\section{Figures}

Figure 1. Map of the hydrographic Great Basin, sage-grouse management zones, and locations of

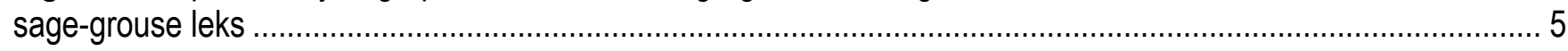

Figure 2. Map of Resilience and Resistance (R\&R) index classes in the Great Basin ........................................ 9

Figure 3. Map of estimated sage-grouse core areas and associated distribution of breeding leks in the

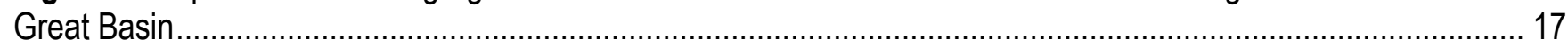

Figure 4. Relation between total burned area (acute) and time by low $(<32.3 \mathrm{~cm})$ and high $(>32.3 \mathrm{~cm})$ precipitation years in the Great Basin from 1984 to 2013

Figure 5. Increases in burned area (cumulative) by R\&R index class across the Great Basin from 1984 to 2013

Figure 6. Map of cumulative burned area by R\&R index class across the Great Basin as of 2013 ....................... 21

Figure 7. Effect of distance to burn perimeter on the annual population rate of change $(\lambda)$ of sage-grouse across the Great Basin from 1985 to 2014

Figure 8. Effect of cumulative burned area (square-km) on the annual population rate of change $(\lambda)$ of sage-grouse across the Great Basin from 1985 to 2014. 
Figure 9. Three-dimensional display of the interaction effects between precipitation (spring through fall) and cumulative burned area on population rate of change $(\lambda)$ of sage-grouse in the Great Basin from 1985 to $2014 \ldots 27$

Figure 10. Observed and predicted changes in cumulative burned area over time by R\&R class

Figure 11. Thirty year predictions for proportion of sage-grouse populations remaining in the Great Basin given modeled effects of cumulative fire on rates of change under projected median (50th percentile; A), low (25th percentile; B), and high (75th percentile; $C$ ) amounts of precipitation during spring, summer, and fall..... 30 Figure 12. Examples illustrating how 25, 75, and 99 percent reductions in cumulative burned area in core areas relative to no reductions in burned area outside core areas might influence projected sage-grouse population rate of change $(\lambda)$ over the next 30 years under low, median, and high amounts of precipitation

\section{Tables}

Table 1. Simplified index for overall resilience to disturbance and resistance to cheatgrass invasion (R\&R) predicted by soil temperature/moisture regimes underlying sagebrush habitats in the Great Basin

Table 2. Summary of fire recovery models used to evaluate how sage-grouse population growth rates were best explained by variation in post-recovery times relative to R\&R index class.

Table 3. Description of parameters in the mixed effects model for sage-grouse annual population rate of change $(\lambda)$ in the Great Basin from 1985 to 2013, based on density, wildfire, climate, and interaction effects, and random effects among lek sites and years.

Table 4. Description of parameters in the model for estimating change in cumulative fire area within $5 \mathrm{~km}$ of leks in the Great Basin from 1984 to 2013.

Table 5. Descriptive statistics for number of leks counted per state, male lek attendance, corresponding number of estimates of annual population rate of change $(\lambda)$ used as response variables in Bayesian modeling of wildfire, precipitation, and density effects on sage-grouse in the Great Basin from 1985 to 2013.

Table 6. Ranking and selection of models formulated to identify the best combination of wildfire, precipitation, and density predictor variables influencing 30-year patterns of sage-grouse population growth across the Great Basin based on change in Deviance Information Criterion $(\Delta \mathrm{DIC})$.

\section{Conversion Factors}

International System of Units to Inch/Pound

\begin{tabular}{|c|c|c|}
\hline Multiply & By & To obtain \\
\hline \multicolumn{3}{|c|}{ Length } \\
\hline millimeter $(\mathrm{mm})$ & 0.03937 & inch (in.) \\
\hline centimeter $(\mathrm{cm})$ & 0.3937 & inch (in.) \\
\hline meter (m) & 3.281 & foot $(\mathrm{ft})$ \\
\hline kilometer $(\mathrm{km})$ & 0.6214 & mile (mi) \\
\hline \multicolumn{3}{|c|}{ Area } \\
\hline square meter $\left(\mathrm{m}^{2}\right)$ & 10.76 & square foot $\left(\mathrm{ft}^{2}\right)$ \\
\hline square meter $\left(\mathrm{m}^{2}\right)$ & 0.0002471 & acre \\
\hline hectare (ha) & 2.471 & acre \\
\hline sauare hectometer $\left(\mathrm{hm}^{2}\right)$ & 2.471 & acre \\
\hline square kilometer $\left(\mathrm{km}^{2}\right)$ & 0.3861 & sauare mile $\left(\mathrm{mi}^{2}\right)$ \\
\hline square kilometer $\left(\mathrm{km}^{2}\right)$ & 247.1 & acre \\
\hline
\end{tabular}




\title{
Long-Term Effects of Wildfire on Greater Sage-Grouse- Integrating Population and Ecosystem Concepts for Management in the Great Basin
}

\author{
By Peter S. Coates ${ }^{1}$, Mark A. Ricca ${ }^{1}$, Brian G. Prochazka1', Kevin E. Doherty², Mathew L. Brooks', and \\ Michael L. Casazza ${ }^{1}$
}

\begin{abstract}
Greater sage-grouse (Centrocercus urophasianus; hereinafter, sage-grouse) are a sagebrush obligate species that has declined concomitantly with the loss and fragmentation of sagebrush ecosystems across most of its geographical range. The species currently is listed as a candidate for federal protection under the Endangered Species Act (ESA). Increasing wildfire frequency and changing climate frequently are identified as two environmental drivers that contribute to the decline of sagegrouse populations, yet few studies have rigorously quantified their effects on sage-grouse populations across broad spatial scales and long time periods. To help inform a threat assessment within the Great Basin for listing sage-grouse in 2015 under the ESA, we conducted an extensive analysis of wildfire and climatic effects on sage-grouse population growth derived from 30 years of lek-count data collected across the hydrographic Great Basin of Western North America. Annual (1984-2013) patterns of wildfire were derived from an extensive dataset of remotely sensed 30-meter imagery and precipitation derived from locally downscaled spatially explicit data. In the sagebrush ecosystem, underlying soil conditions also contribute strongly to variation in resilience to disturbance and resistance to plant community changes (R\&R). Thus, we developed predictions from models of post-wildfire recovery and chronic effects of wildfire based on three spatially explicit R\&R classes derived from soil moisture and temperature regimes. We found evidence of an interaction between the effects of wildfire (chronically affected burned area within 5 kilometers of a lek) and climatic conditions (spring through fall precipitation) after accounting for a consistent density-dependent effect. Specifically, burned areas near leks nullifies population growth that normally follows years with relatively high precipitation. In models, this effect results in long-term population declines for sage-grouse despite cyclic periods of high precipitation. Based on 30-year projections of burn and recovery rates, our population model predicted steady and substantial long-term declines in population size across the Great Basin. Further, example management scenarios that may help offset adverse wildfire effects are provided by models of varying levels of fire suppression and post-wildfire restoration that focus on areas especially important to sage-grouse populations. These models illustrate how sage-grouse population persistence likely will be compromised as sagebrush ecosystems and sage-grouse habitat are degraded by wildfire, especially in a warmer and drier climate, and by invasion of annual grasses that can increase wildfire frequency and size in the Great Basin.
\end{abstract}

\footnotetext{
${ }^{1}$ U.S. Geological Survey.

${ }^{2}$ U.S. Fish and Wildlife.
} 


\section{Introduction}

Contemporary theoretical and applied ecology has focused increasingly on understanding the processes and management of alternative ecosystem states, whereby recognizing that disturbances can profoundly alter underlying processes that shape ecosystems and reorganizes community composition and species abundance (Scheffer and others, 2001; Beisner and others, 2003). Importantly, variation in disturbance intensity and effects on underlying processes can either allow an ecosystem to recover and ultimately retain its pre-disturbance state (that is, 'helpful resilience'), or drive it to a persistent alternative state with new functional processes once a disturbance threshold has been surpassed (that is, 'unhelpful resilience') (Standish and others, 2014). In the latter case, hysteresis can become operative if recovery is decoupled from pathways that maintained the pre-disturbance state (Suding and others, 2004). Moreover, lack of resistance to invading species can result in altered species composition following disturbance events, which can result in a positive feedback that drives an ecosystem further away from its original state (Suding and others, 2004). These state-changing mechanisms ultimately may yield an ecosystem that has no historical analog (Seastedt and others, 2008; Hobbs and others, 2009). Accordingly, emphasis recently has been placed on managing ecosystems for resilience to disturbance and resistance to invasive species (R\&R). In this case, factors that may change ecosystem processes and disturbance thresholds are identified so that resources for restoration can be allocated most effectively and with a higher probability of success (Seastedt and others, 2008; Chambers and others, 2014a; Standish and others, 2014). Equally important is identifying how populations of constituent species inhabiting these ecosystems respond to disturbance and subsequent ecosystem transitions along ecologically meaningful time-frames (Agrawal and others, 2007). It follows that managing for R\&R can be improved by integrating concepts from ecosystem and population ecology.

Habitat degradation within the Great Basin ecoregion of the Intermountain West of North America is a contemporary example of how disturbance is driving rapid changes in ecosystem structure and function across enormous spatial scales. The hydrographic Great Basin comprises more than 72.7 million ha across five States. The vastness of the affected area results in strong ecological and sociopolitical ramifications. Wildfire has been identified as a primary disturbance leading to shifts in ecosystem state and concomitant declines in sagebrush-steppe obligate species in the Great Basin (Brooks and Pyke, 2001; Connelly and others, 2011; Miller and others, 2011; Chambers and others, 2014b). Nearly all species of sagebrush (Artemisia spp.) in the Great Basin are killed by wildfire and do not re-sprout (Schlaepfer and others, 2014). At the landscape level, wildfire frequency and magnitude have increased significantly subsequent to invasion of annual grasses, particularly cheatgrass (Bromus tectorum) and medusahead-rye (Taeniatherum canput-medusae) following disturbance in the Great Basin. Annual grass invasion acts as a positive feedback for spreading wildfire to adjacent stands of intact sagebrush (that would otherwise be less likely to burn) and subsequent re-burning over shorter return intervals (for example, D'Antonio and Vitousek, 1992; Brooks and others, 2004; Chambers and others, 2007; Balch and others, 2013; Baruch-Mordo and others, 2013; Chambers and others, 2014a). Depending on local soil temperature and moisture regimes influencing variation in $R \& R$ (Chambers and others, 2014a, 2014b; Brooks and others, in press), the end result can be an ecosystem with novel, albeit deleterious and hysteretic, properties (for example, altered water and nutrient cycling, diminished wildlife and livestock value, and higher susceptibility to disturbance effects) (Miller and others, 2011).

From a population ecology perspective, greater sage-grouse (Centrocercus urophasianus, hereinafter referred to as "sage-grouse") are an umbrella or indicator species for the ecological health and integrity of sagebrush ecosystems at large spatial scales (Rowland and others, 2006; Knick and Connelly, 2011). Sage-grouse populations have declined concomitantly with the loss and degradation of sagebrush ecosystems and sage-grouse now occupy approximately one-half of their former range 
(Schroeder and others, 2004; Knick and Connelly, 2011). Following an initial ruling of warranted but precluded (U.S. Fish and Wildlife Service, 2010), sage-grouse are now classified as warranted for listing under the Endangered Species Act (ESA) with a final determination scheduled for September 2015. Increased recognition of risks posed by interactions between wildfire, drought, and invasive annual grasses to the ecological and socio-economic integrity of sagebrush ecosystems and threats to the persistence of sage-grouse populations led to the recent issuance of Secretarial Order 3336, which aims to improve strategies for fire suppression and post-wildfire restoration across the Great Basin (U.S Department of the Interior, 2015).

Critical to these efforts is a sound understanding of how sage-grouse populations respond demographically to variation in the frequency and extent of wildfire, post-wildfire recovery times related to R\&R, and interactions with climate and resource availability across large spatial scales. Most studies of sage-grouse-wildfire relations have been site-specific and focused either on effects of prescribed fire on sage-grouse population growth (Connelly and others, 2000a), movements and habitat associations (Fischer and others, 1996, 1997; Nelle and others, 2000; Rhodes and others, 2010), shorterterm ( $<10$ year) effects of wildfire and climate on population growth (Blomberg and others, 2012) and habitat suitability (Davis and Crawford, 2014), or relied primarily on simulations (Pedersen and others, 2003). No analyses to date have linked multi-decadal patterns of wildfire across the Great Basin with concomitant data on sage-grouse population dynamics and climate. Such an analysis is important because it would provide a means for identifying mechanisms driving prevailing trends in sage-grouse population size and predict long-term population change while reducing the chance of mistaken inference arising from examining short-term data only. For example, given sage-grouse population cycles over time, examining short-term data alone may reveal transient spikes that run counter to actual long-term trajectories. Long-term evaluation may identify populations that are most at risk from wildfire or changing climate and lead to more effective targeting of management resources for conservation of sagebrush and sage-grouse populations.

Species using central-placed breeding strategies, such as lek breeding sage-grouse, are wellsuited to spatially explicit and large-scale analyses of the effects of environmental and demographic stochasticity on population growth rate. One hypothesis of lek evolution posits that leks are located in nesting habitat where males are most likely to encounter females for breeding opportunities (Gibson and Langen, 1996), and several studies support this mechanism for sage-grouse (Schroeder and White, 1993; Gibson, 1996; Holloran and Anderson, 2005; Doherty and others, 2010, 2011; Coates and others, 2013). Hence, measurements of the extent and persistence of wildfire along with the timing and amount of precipitation within biologically relevant distances to leks should be good predictors of sage-grouse population growth rates determined from lek counts across the Great Basin. The prior absence of such an analysis across broad temporal and spatial scales in the Great Basin in large part is due to the difficulty in gathering lek count data, which normally is collected on a state-by-state basis, and forming spatially explicit wildfire and climate data from records within State and Federal databases. Now, these data have been compiled by the Western Association of Fish and Wildlife Agencies, Monitoring Trends in Burn Severity (Eidenshink and others, 2007), and PRISM Climate Group (Daly and others, 2008). In addition, spatially explicit data describing landscape-level variation in R\&R based on measurable environmental gradients of elevation, aspect, and precipitation that influence soil temperature and moisture regimes in the Great Basin have been developed recently (Campbell, 2014; Chambers and others, 2014b). Hence, sage-grouse population trends can be linked directly to probabilities of ecosystem state transition and variation in post-wildfire recovery times derived from wildfire-related disturbance activity and underlying $R \& R$, while simultaneously accounting for other sources of 
environmental (for example, precipitation) (Blomberg and others, 2012) and demographic (for example, density dependence) (Garton and others, 2011, 2015) stochasticity that can be similarly strong determinants of sage-grouse population growth patterns.

The objectives of the report were 3-fold:

1. Model sage-grouse population growth as a function of wildfire, precipitation, and densitydependence over a 30-year period (1985-2013) at leks with different underlying R\&R properties across the Great Basin. Our modeling approach identifies influential environmental drivers that are thought to explain variation in population growth rates through time, rather than modeling growth rate explicitly as a function of time. Thus, factors that are thought to be responsible for the cyclic patterns (Fedy and Aldridge, 2011) of sage-grouse population growth were modeled explicitly.

2. Predict future (for example, next 30 years) patterns of sage-grouse population rate of change based on R\&R-specific projections of cumulative burned area within close (that is, $5 \mathrm{~km}$ ) proximity of breeding leks across the Great Basin while accounting for variation in precipitation and density-dependence effects.

3. Evaluate projected patterns of sage-grouse population decline across multiple example management scenarios that target varying levels of reduction of wildfire in areas with the greatest sage-grouse habitat quality and breeding densities.

\section{Description of Study Area}

Our study encompassed nearly $650,000 \mathrm{~km}^{2}$ within the hydrographic boundary of the Great Basin. It comprises parts of five States (Nevada [43 percent], Utah [17 percent], Idaho [16 percent], Oregon [14 percent], and California [10 percent]) and four Sage-Grouse Management Zones (MZ III Southern Great Basin [47 percent], MZ IV - Snake River Plain [33 percent], MZ V - Northern Great Basin [19 percent], and MZ II - Wyoming Basins [1 percent]) (fig. 1). Across the Great Basin, elevation ranges from 400 to 3,000 $\mathrm{m}$ within a mosaic of mountain ranges and lowland basins (Miller and others, 2013). Most precipitation falls in winter, and ranges annually from 150 to $300 \mathrm{~mm}$ in southern regions and at low elevations, and 300-400 $\mathrm{mm}$ in more northern regions and at mid-to-high elevations. Plant communities assemble along elevation and precipitation gradients, ranging from salt-desert shrublands in dry-lowland basins to Wyoming big sagebrush (Artemisia tridentate wyomingensis) associations in semi-arid regions to mountain big sagebrush (Artemisia tridentata vaseyana), mixed montane shrubland, pinyon pine (Pinus spp.) and juniper (Juniperus spp.) woodland, and coniferous forest associations in wetter and higher elevation regions.

The sampling area (grain) of our study specifically focused on areas within $5 \mathrm{~km}$ of sage-grouse leks, areas which primarily are comprised of sagebrush communities. These sagebrush communities occur on 63 percent of landscapes within the western range of sage-grouse populations (Brooks and others, 2015) and encompass over 80 percent of areas within $5 \mathrm{~km}$ of leks. Sagebrush communities can be partitioned into sagebrush steppe occupying more northern areas lying within high precipitation zones where sagebrush and perennial grasses co-dominate, and Great Basin sagebrush occupying drier and warmer southern areas where perennial grasses are less common (Küchler, 1970; Miller and others, 2011) with relatively low rates of annual net primary production (Noy-Meir, 1973). The timing and length of the wildfire season within the geographical range of sage-grouse in the Great Basin can vary widely among years, but generally begins in June and ends in September (Brooks and others, 2015). The amount of fire area, fire recurrence, and fire rotation also can vary widely among sage-grouse management zones and vegetation types in the Great Basin. 


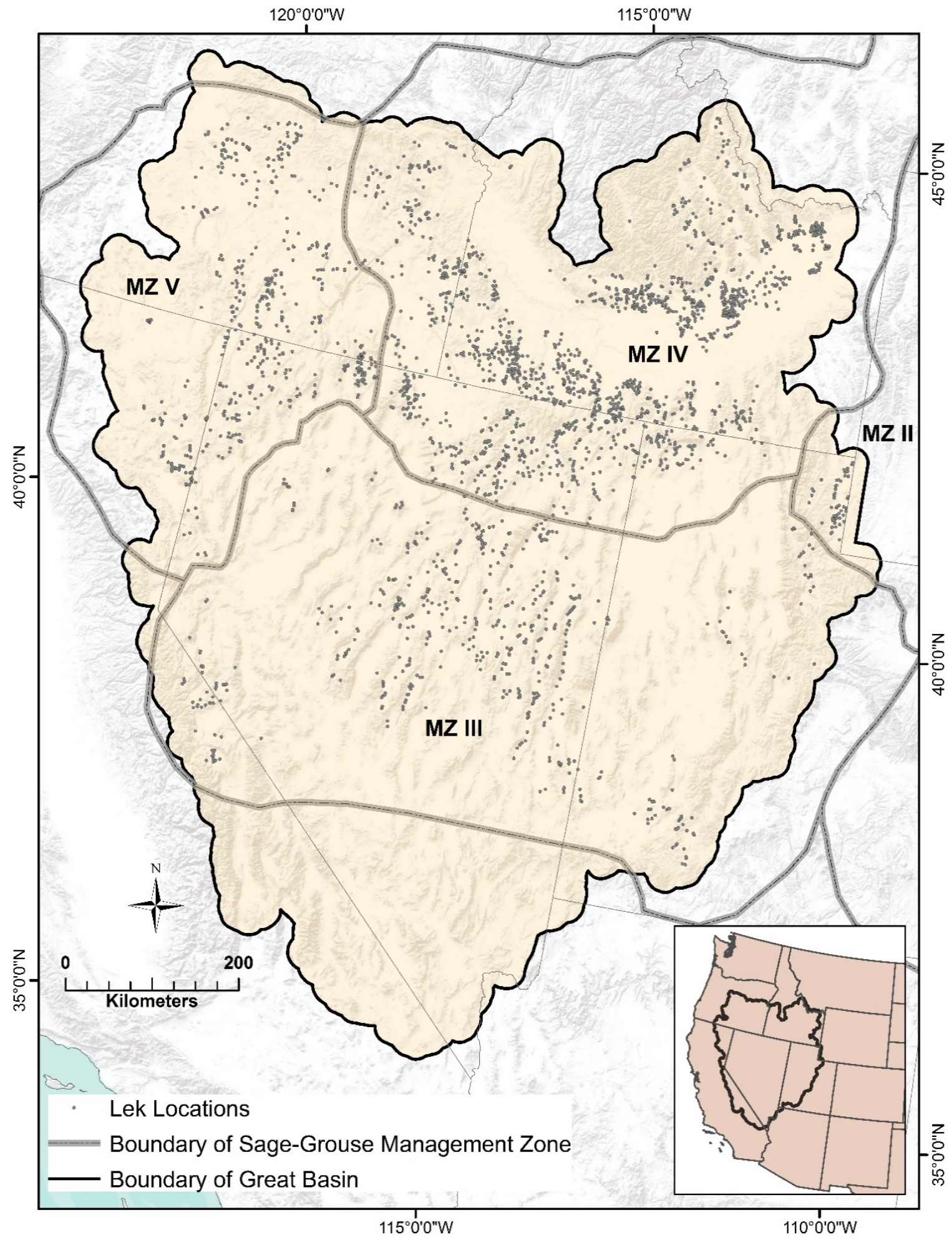

Figure 1. Map of the hydrographic Great Basin, sage-grouse management zones, and locations of sage-grouse leks. 


\section{Methods}

\section{Data Sources}

\section{Lek Counts}

Counts of male sage-grouse attending breeding leks provide reliable and widely used spatially explicit data for analyses of population trends (Fedy and Aldridge, 2011). State fish and wildlife agencies use established protocols for defining leks, counting male sage-grouse at leks, and systematically searching for new leks. Counts of males at leks are typically conducted 3-4 times per season and the maximum count is recorded (Connelly and others, 2003). We used data from annual lek counts collected by all agencies within the Great Basin from 1985 to 2014. This time frame was selected to coincide with the range of available wildfire and climate data (see sections, "Annual Wildfire" and "Precipitation"). Because protocols and data treatments can vary slightly among agencies, data were compiled and subjected to further quality control and assurances (QA/QC) by the Western Association of Fish and Wildlife Agencies (2015). These QA/QC included: (1) removing counts obtained by aerial survey owing to lower probabilities of detection associated with this method; (2) removing counts obtained outside conventional calendar (March 15-May 15) periods and early morning hours (earlier than 0.5 hours before sunrise or later 1.5 hours after sunrise); (3) removing counts comprised entirely of birds of unknown gender; (4) combining leks within $1.2 \mathrm{~km}$ of each other in order to pool likely satellite leks into a single lek cluster; and (5) assuming that a recorded count of zero equaled no males were observed and a blank value indicated the lek was not counted or not available (NA); and (6) removing consecutive zero counts bracketed by non-zero-zero and zero-non-zero counts (see section, "Population Rate of Change"). For example, the sequence of counts $\{50,0,0,0,100\}$ would become $\{50,0$, NA, 0 , $100\}$; another sequence $\{50,0,0,100\}$ would stay $\{50,0,0,100\}$; and $\{50,0,0,0\}$ would become $\{50$, $0, \mathrm{NA}, \mathrm{NA}\}$.

\section{Annual Wildfire}

Spatially explicit data on wildfire extent and severity in the Great Basin extent from 1984 to 2013 were downloaded from the Monitoring Trends in Burn Severity (MTBS) database (http://mtbs.gov/index.html) (Eidenshink and others, 2007). Only burned surface areas greater than 405 ha as a result of wildfires were included in the Western United States portion of the MTBS database, yet these wildfires account for more than 95 percent of burned surface-area in the Western United States (Eidenshink and others, 2007) and 96 percent are within the range of the sage-grouse (Brooks and others, 2015). These data are generated by MTBS using several steps. Scenes are first identified using digitized fire histories from agency databases, other fire records, and peak photosynthetic activity estimates from Advanced Very High Resolution Radiometer (AVHRR) satellite data. Normalized burn ratio (NBR) indices are then calculated using thermal mapping (TM) bands from corresponding $30-\mathrm{m}^{2}$ Landsat pre- and post-fire imagery, where

$$
\mathrm{NBR}=\frac{\mathrm{TM} 4-\mathrm{TM} 7}{\mathrm{TM} 4+\mathrm{TM} 7}
$$


Bands of red light are measured with TM4 and longer short-wave infrared bands are measured with TM7. Values for differenced normalized burn ratios (dNBR) are then calculated by subtracting postfrom pre-fire NBR values. Values for $\mathrm{dNBR}$ are then binned into five ecologically relevant fire severity classes: (0) increased greenness; (1) unburned to low, (2) low; (3) moderate; and (4) high. Fire perimeters are digitized around fire-severity classes 1 through 4 , which indicate some minimum level of fire-associated changes in vegetation. Because we were most concerned with quantifying effects of wildfire stemming from fire-driven changes in vegetation (and not overestimating effects of wildfire on sage-grouse population growth), we excluded fire-severity class 1 values that likely result in minimal vegetation change, and reclassified fire-severity classes 2,3 , and 4 values into a single binary raster using Spatial Analyst in ArcGIS ${ }^{\mathrm{TM}}$ 10.1. Hence, we erred on the side of reducing commission error rather than omission error (that is, we excluded those low-severity areas that may have actually burned rather than including low-severity areas that did not burn), and revised fire perimeters were redrawn around pixels representing likely vegetation change as a result of wildfire.

\section{Precipitation}

Spatially explicit data for local measurements of precipitation at a spatial resolution of $4 \mathrm{~km}$ from 1985 to 2013 were obtained from the PRISM Climate Group (http://www.prism.oregonstate.edu/), and then downscaled to $800 \mathrm{~m}$ (P. Flint and L. Flint, U.S. Geological Survey, unpub. data, 2014). We chose to index climatic effects on sage-grouse population rate of change according to variation in annual and seasonal precipitation (see section, "Model Covariates," for rationale). We restricted our analyses to include variables related to precipitation to limit the number of covariates in our climatic model set, and because effects due to precipitation are more readily explained from a perspective of sage-grouse lifehistory (for example, relations between rainfall, primary productivity, and available resources for grouse) than from extremes in temperature, particularly for a cold-adapted gallinaceous species.

\section{Resilience and Resistance}

Extensive research effort in recent years has been devoted to determining how sagebrush ecosystem structure and function influences resilience to disturbance and resistance to annual grass invasion. In general, R\&R increases along a gradient based on elevation and aspect that correlates with variation in soil moisture and temperature, where corresponding habitats with underlying cold or cool and moist soils have higher R\&R than habitats with underlying warm and dry soils (Chambers and others, 2014a, 2014b). To create a landscape level surface depicting broad patterns in underlying $R \& R$ processes, three broad classes that index resilience to wildfire-related disturbance and resistance to annual grass invasion (that is, high, moderate, and low; table 1, fig. 2) were created by the Fire and Invasive Assessment Team (FIAT) from finer scale soil temperature and moisture subclass data extracted from maps developed by Campbell (2014). Although data were unavailable to classify some areas in the southern portion of the Great Basin, the R\&R classification encompassed all sage-grouse leks and areas surrounding leks that were relevant to this analysis. We then used R\&R index classes to calculate different recovery times in calculations of cumulative burned area and chronic wildfire effects (as described in section, "Wildfire"). 
Table 1. Simplified index for overall resilience to disturbance and resistance to cheatgrass invasion (R\&R) predicted by soil temperature/moisture regimes underlying sagebrush habitats in the Great Basin.

[Derived by the Fire and Invasive Assessment Team based on Chambers and others (2014b) and Campbell (2014). Sagebrush habitats excludes aquic or oxyaquic soils, which generally are too moist to support sagebrush species, as well as ustic (summer moist) moisture regimes (for example, wetlands, lakes)]

\begin{tabular}{lll}
\multicolumn{1}{c}{$\begin{array}{c}\text { Soil temperature/moisture regime - moisture } \\
\text { subclass }\end{array}$} & \multicolumn{1}{c}{ Common name } & R\&R index \\
\hline Cryic/Xeric-Typic & Cold/moist & High \\
Cryic/Aridic bordering on Xeric & Cold/dry bordering on moist & High \\
Frigid/Xeric-Typic & Cool/moist & High \\
Cryic/Aridic-Typic & Cold/dry & Moderate \\
Cryic/Xeric bordering on Aridic & Cold/moist bordering on dry & Moderate \\
Frigid/Xeric bordering on Aridic & Cool/moist bordering on dry & Moderate \\
Frigid/Aridic-Typic & Cool/dry & Moderate \\
Frigid/Aridic bordering on Xeric & Cool/dry bordering on moist & Moderate \\
Mesic/Xeric-Typic & Warm/moist & Moderate \\
Mesic/Aridic bordering on Xeric & Warm/dry bordering on moist & Low \\
Mesic/Aridic-Typic & Warm/dry & Low \\
Mesic/Xeric bordering on Aridic & Warm/moist bordering on dry & Low \\
\hline
\end{tabular}




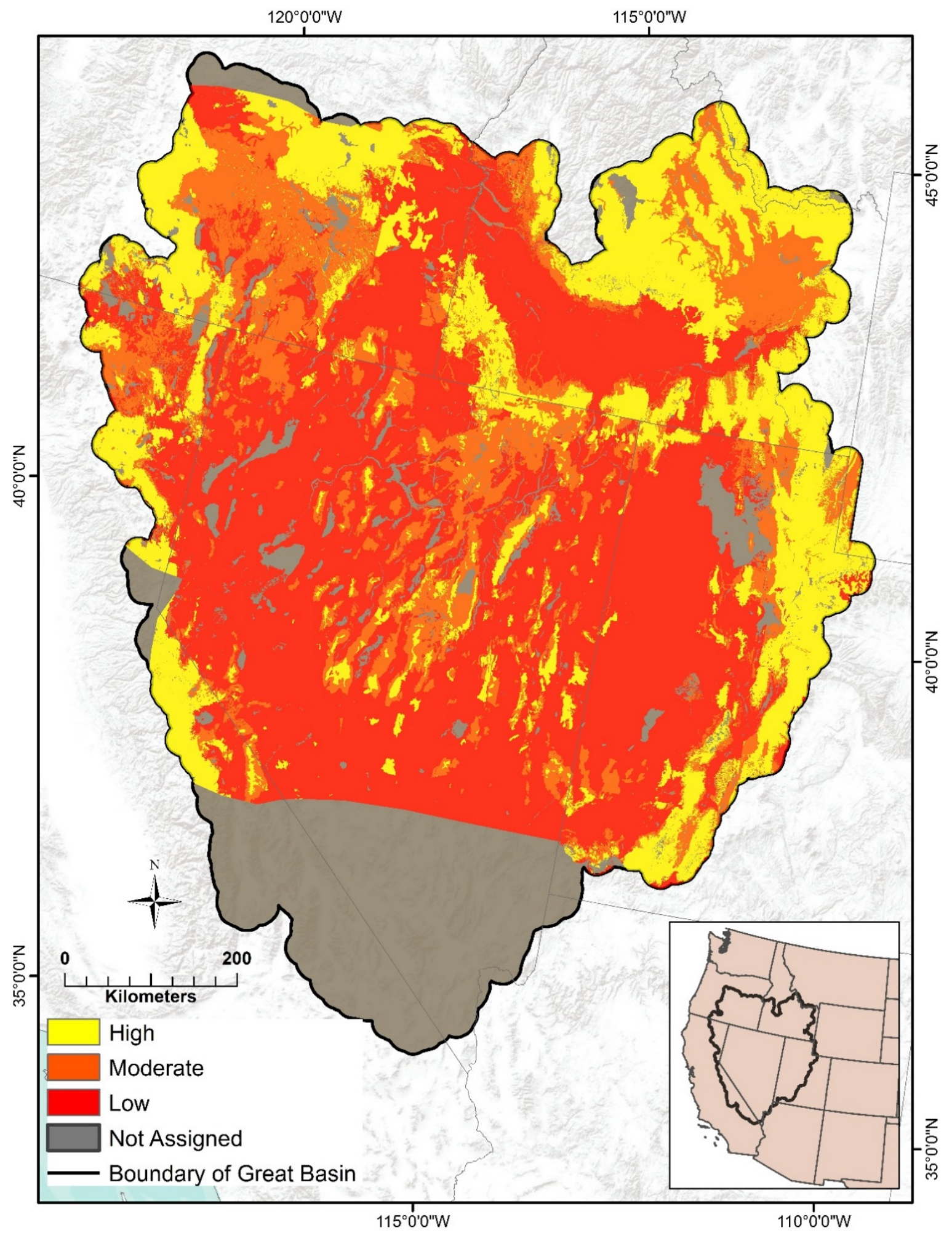

Figure 2. Map of Resilience and Resistance (R\&R) index classes in the Great Basin. Classification of R\&R were derived from soil moisture and temperature subclasses from Campbell (2014). 


\section{Model Response and Covariate}

\section{Population Rate of Change}

We calculated the instantaneous (or intrinsic) annual per-capita rate of change ( $r$; Gotelli and Ellison, 2004) for sage-grouse populations, which took the form:

$$
r_{i j}=\ln \frac{\mathrm{N}_{i j}}{\mathrm{~N}_{i j-1}}
$$

where $\mathrm{N}$ represents maximum male lek count, $i$ represents lek, $j$ represents year, and $j-1$ represents a previous year. We used $r$ as the response variable in all predictive models for population growth (see section, "Modeling Wildfire and Climate Effects on Population Growth"). We added a constant of 0.1 to all counts to avoid division by zero when no birds were detected at $N_{i j}$. Where applicable for illustration and interpretation purposes, we convert to finite rates of change ( $\lambda$; Caswell, 2001; Gotelli and Ellison, 2004), and expressed as:

$$
\lambda=e^{r}
$$

\section{Density-Dependence}

We formulated models to test and account for density-dependent reductions in population growth observed within some sage-grouse populations (Garton and others, 2011, 2015). Densitydependence from time-series data are typically evaluated using Ricker (Dennis and Taper, 1994) and Gompertz (Dennis and others, 2006) methods that estimate population rate of change as a function of raw and logarithmic abundance, respectively. Furthermore, time lags can be incorporated to model delayed density-dependent feedbacks that can yield cyclic patterns of population growth often displayed by sage-grouse in Wyoming (Fedy and Aldridge, 2011; Fedy and Doherty, 2011). Recent analyses of stochastic population growth from 1965 to 2013 found consistent support for Gompertz-type densitydependence lagged one-year $\log \left[N_{j-2}\right]$ ); hereinafter, 'lag-Gompertz') across all sage-grouse management zones encompassed by our study area (Garton and others, 2015). To allow interpretation across studies, we a priori selected lag-Gompertz to be tested against the null model without predictors, and, if supported by the data, then carried this effect forward for inclusion in all predictive models.

\section{Wildfire}

Wildfire effects on sage-grouse population growth were indexed with three spatially explicit covariates derived from the MTBS data for each year: (1) distance to burned perimeter; (2) burned area; and (3) wildfire perimeter-to-area (PA) ratio (an index for amount burned to unburned edge). Distance to burned perimeter measured the Euclidean distance between lek centers and nearest burned edge (zero distance if lek was inside the fire area), and allowed for estimation of 'burn over' effects (for example, wildfires that completely burned over lek centers). Burned area and PA ratio within circular buffers of $5 \mathrm{~km}\left(78.5 \mathrm{~km}^{2}\right)$ and $10 \mathrm{~km}\left(314 \mathrm{~km}^{2}\right)$ from lek centers were extracted from raster layers created from corresponding moving windows of 5,160 and 10,560 m, respectively. These distances bracketed the range of values proposed for limiting surface-disturbance near leks (Coates and others, 2013; Manier and others, 2014) and encompassed most nesting habitat as described previously. Burned area represented the amount of fire-severity class 2 through 4 within a wildfire perimeter, and PA ratio represented the amount of total burned edge relative to its total area. 
Burned area and PA ratio also were calculated with two methods. Annual time series analyses typically measure fire dynamics as a spatially static and ephemeral covariate, whereby landscapes burn at particular extents (area) and configurations (PA ratio) in a given year, but burns do not compound across years (that is, annual estimates of burn reset to zero at the conclusion of the fire year) (for example, Baker, 2006; Miller and others, 2011). We term this an 'acute' effect, whereby wildfire influences on population rate of change were modeled as a discrete process confined to a single year (for example, immediate effects of wildfire) (table 2). In contrast, wildfires can have long-lasting effects based on longer term reduction of resources necessary to sage-grouse (for example, loss of sagebrush cover and annual grass invasion), and the recovery time of these resources were then modeled as a function of underlying soil moisture and temperature processes influencing R\&R. We term this a 'chronic' effect, whereby persistence of wildfire scars and associated effects on sage-grouse varied across years according to the predominant underlying R\&R index class within $5 \mathrm{~km}$ of leks (for example, longer term effects of wildfire) (table 2). Evaluating both acute and chronic effects allowed for an investigation of immediate impacts (that is, temporary displacement of sage-grouse) versus those that are long-lasting and likely associated with changes in land cover (that is, reduced local persistence). Recovery times for chronically affected areas (hereinafter, chronic areas) were based on a published meta-analysis of post-wildfire recovery in mountain big sagebrush communities that ranged from 1.28 percent of pre-fire sagebrush per year ("slow-track") to 2.28 percent ("fast-track") per year (Baker, 2011). Mountain big sagebrush communities are among the most resilient of all big sagebrush types, and by assuming their fast-track and slow-track recovery rates for our high and moderate R\&R index classes, respectively, we modeled a "best case scenario" of sagebrush recovery that likely underestimates the length of time to recovery for other sagebrush types (for example, Wyoming big sagebrush).

Table 2. Summary of fire recovery models used to evaluate how sage-grouse population growth rates were best explained by variation in post-recovery times relative to R\&R index class.

[Years to recovery for high and moderate $\mathrm{R} \& \mathrm{R}$ classes were calculated as 20 percent divided $p$, where $p$ is the fast-track (2.28 percent per year) or slow-track rate (1.28 percent per year) of recovery, respectively]

\begin{tabular}{lccc}
\hline \multicolumn{1}{c}{ Fire effect } & Recovery scenario & R\&R index class & Years to recovery \\
\hline Acute & NA & NA & 1 \\
Chronic & Normal & High & 9 \\
& & Moderate & 16 \\
& Low & NA \\
& & High & 5 \\
& Accelerated & Moderate & 8 \\
& & Low & NA \\
& & & 18 \\
& Decelerated & High & 30 \\
& & Moderate & NA \\
\hline
\end{tabular}


By conservatively defining recovery as a minimum threshold of 20 percent pre-fire sagebrush cover within $5 \mathrm{~km}$ of leks necessary to fulfill important sage-grouse life history requirements (for example, brood-rearing and wintering) (Connelly and others, 2000b), we constructed three scenarios of 'normal', 'accelerated', and 'decelerated' recovery times for high and moderate R\&R pixels. These scenarios represent variation in recovery times across a broader range of sagebrush ecosystems (Baker, 2006, 2011; Nelson and others, 2014). Under the 'normal' scenario, we calculated recovery time of high R\&R pixels to 20 percent of pre-fire sagebrush using the fast-track rate ( 2.28 percent) as 9 years, (that is, 20 divided by 2.28 , rounded to the nearest whole number) while recovery of moderate R\&R pixels to 20 percent sagebrush using the slow-track rate (1.28 percent) occurred after 16 years (that is, 20 divided by 1.28 , rounded to the nearest whole number). We cut normal recovery times approximately in onehalf for the 'accelerated' scenario ( 5 and 8 years for high and moderate R\&R pixels, respectively). We doubled recovery times under the 'decelerated' scenario but these were not allowed to exceed the 30year span of the data (18 and 30 years for high and moderate R\&R pixels, respectively). In all scenarios, the 'recovery clock' reset to zero if a new wildfire burned over a previously burned pixel with high or moderate $R \& R$ before recovery occurred. In contrast, we did not allow for any recovery in low $R \& R$ pixels, and assumed permanent conversion to annual grass following fire. This assumption was based on: (1) slow recovery following fire in Wyoming big sagebrush communities that often comprise low R\&R habitat (for example, $<5$ percent of pre-fire sagebrush cover typically returns after 25 years) (Miller and others, 2011); and (2) the high likelihood of state-transition without extensive management intervention (Chambers and others, 2014a, 2014b). Hence, burned low R\&R pixels represented a permanent wildfire-scar and loss of resources available to sage-grouse.

We recognize that full recovery within $5 \mathrm{~km}$ of leks can take much longer than our three R\&Rbased recovery scenarios suggest. However, modeling full recovery in more resilient mountain big sagebrush and perennial grass communities or less resilient and low-elevation Wyoming big sagebrush communities was untenable because the 30 years of available MTBS data fell short of including the full range of years required for full recovery in both communities (ca. 25-120 years) (Baker, 2006, 2011). Hence, these assumptions allowed for relatively quick return of some recovery-based benefits to sagegrouse (based on an estimated post-fire 20 percent return of sagebrush) that ameliorated the chronic wildfire effect for leks dominated by high and moderate $R \& R$, and no recovery in low R\&R represented by cheatgrass invasion.

\section{Precipitation}

Similar to the wildfire covariates, we extracted mean precipitation data within 5- and 10-km radius buffers from lek centers using raster layers created from moving windows of 5,160 and 10,560 m, respectively. We aggregated precipitation into seasonal (spring, summer, fall, and winter) and annual intervals based on a priori hypotheses that synchronized with the timing of sage-grouse life stages. For example, spring spanned March to May and indexed resources available during the sage-grouse nesting period (for example, forb growth), whereas summer spanned June to August and indexed resources available during the brood-rearing period (for example, wet meadow productivity, delay of plant senescence). We classified fall as September through November to represent spurts of new growth during extended brood-rearing that could increase survival of juveniles entering winter. Winter spanned December to February, and indexed precipitation (primarily as snow) that contributed to increased runoff that was thought to drive more productive and possibly longer growing seasons. We also formed four multi-season groups by combining: (1) spring and summer (nesting + brood rearing); (2) spring, 
summer, and fall (nesting + brood rearing + extended brood rearing/juvenile); (3) winter, spring, and summer (snowpack runoff + nesting + brood rearing); and (4) annual (total across all seasons). Heavy snowfall during winter also can influence overwinter mortality and thus subsequent numbers of birds that survive to the following years' lek count (Anthony and Willis, 2009). However, other studies indicate relatively high over winter survival (Blomberg and others, 2013), so we aligned winter at the beginning rather than the end of the precipitation year to allow for carry-over effects of winter precipitation (for example, snowpack melt) on plant growth and phenology in the subsequent spring that should affect successful reproduction and increase the potential number of recruits in the next year.

\section{Modeling Wildfire and Climatic Effects on Population Growth}

A two-step Bayesian mixed-effects model framework was used to investigate densitydependence, precipitation, and wildfire as linear predictors for annual population growth rates from 1985 to 2013. Our mixed effects model equation is structured as

$$
\log (\lambda)=\beta_{0}+\sum_{i} \beta_{i} X_{i}+\zeta_{\text {Lek }}+\zeta_{\text {Year }}
$$

where $X_{i}$ represent model covariates to describe density-dependence, climate, and/or wildfire (absent in the null model), the $\beta$ terms represent model coefficient parameters, and the $\zeta$ terms represent random effects variation among leks and years. Bayesian modeling is well suited for generating projections of growth rates and are readily derived from posterior distributions of parameter estimates (Halstead and others, 2011). Thus, we chose to use derived distributions for effects of wildfire (estimated while accounting for variation in precipitation and sage-grouse density) to forecast how future changes in cumulative burned area might influence population trajectories of Great Basin sage-grouse over the next 30 years. Posterior distributions were derived using Program JAGS within the rjags package (Plummer and others, 2015) in R version 3.1.1 (R-Core-Team, 2014). Specifically, posterior distributions of parameter estimates were generated from three chains of 10,000 iterations each, after a burn-in of 10,000 (step 1) to 20,000 (step 2) iterations using Markov-chain Monte Carlo (MCMC) methods. Convergence of MCMC output was assessed visually with history plots and the R-hat statistic, where values $\leq 1.1$ indicated convergence (Gelman and others, 2014).

Posterior distributions of estimated covariate effects were derived from distributions of uninformative prior probabilities (table 3) during both steps, and all models were fitted with the randomeffects structure to account for intraclass correlations associated with leks and years. Step 1 was designed to select and carry-forward the covariates with the most support from groups of variables representing: (1) density-dependence; (2) wildfire; and (3) precipitation. Input data were aligned so that wildfire and precipitation covariates at year $j$ influenced numbers of grouse counted at leks in year $j+1$. Within groups, fitted models representing singular-additive effects were compared against each other, a null model (that is, random effects only), and a density-dependence only model (that is, lag-Gompertz with random effects; when applicable) using deviance information criterion (DIC, lower is better), a goodness-of-fit statistic calculated for every model. Although use of DIC for model selection has limitations (Hooten and Hobbs, 2014), this criteria is commonly used to rank competing Bayesian models because of its computational ease and similarity to maximum-likelihood based Akaike Information Criterion (AIC). Furthermore, we calculated DIC because this criteria is reliable when used with models with similar attributes to those in this study (for example, linear and independent data, large sample size, low number of parameters). We defined three different $\triangle \mathrm{DIC}$ values to facilitate comparisons among models: $\Delta \mathrm{DIC}_{\mathrm{Group}}$ as $\mathrm{DIC}$ minus the minimum DIC value within the same group or 
subgroup, to compare models within each group or subgroup; $\triangle \mathrm{DIC} \mathrm{DD}_{\mathrm{DD}}$ as $\mathrm{DIC}$ minus the DIC of the density-dependent-only model, to compare each model to the Gompertz (1-year lag) density-dependent model; and $\triangle \mathrm{DIC}_{\text {null }}$ as DIC minus the DIC of the null model to compare each model to the random intercept-only model. For each subgroup, single covariate effects were carried forward if they met three criteria: (1) consisted of lowest DIC within the subgroup (that is, $\triangle \mathrm{DIC}_{\text {group }}$ equaled zero); (2) DIC was at least two units less than DIC for the null model (that is, $\triangle \mathrm{DIC}_{\text {null }}$ was less than or equal to negative two); and (3) DIC was at least two units less than DIC for the lag-Gompertz model (that is, $\Delta \mathrm{DIC} \mathrm{DD}_{\mathrm{DD}}$ less than or equal to negative two). Covariates from the models that met these DIC criteria for each group or subgroup were carried forward to step 2.

Table 3. Description of parameters in the mixed effects model for sage-grouse annual population rate of change $(\lambda)$ in the Great Basin from 1985 to 2013, based on density, wildfire, climate, and interaction effects, and random effects among lek sites and years.

[All parameters are estimated using Bayesian techniques assuming minimal prior information, using Uniform (U) or Normal (N) prior distributions, and include baseline $\left(\beta_{0}\right)$, coefficients of effects $\left(\beta_{i}\right)$, random effects $(\zeta)$, and their standard deviations $(\sigma)$. All effects relate to population $\lambda$ according to the equation $\log (\lambda)=\beta_{0}+\sum_{i} \beta_{i} X_{i}+\zeta_{\text {Lek }}+\zeta_{\text {Year }}$, where $X_{i}$ represent model covariates and the summation includes zero (null model), one (lagged-Gompertz only model), or multiple effects]

\begin{tabular}{|c|c|c|}
\hline Symbol & Description & Prior distribution \\
\hline$\sigma_{\mathrm{r}}$ & $\begin{array}{l}\text { Standard deviation for annual per capita instantaneous rate of } \\
\text { increase (model error) }\end{array}$ & $\mathrm{U}(0,50)$ \\
\hline$\beta_{0}$ & Baseline annual per capita instantaneous rate of increase & $\mathrm{U}(-20,20)$ \\
\hline$\beta_{\mathrm{DD}}$ & Coefficient of lagged Gompertz density-dependence effect & $\mathrm{N}\left(0, \sigma_{\mathrm{DD}}\right)$ \\
\hline$\sigma_{\mathrm{DD}}$ & Prior standard deviation $\beta_{\mathrm{DD}}$ & $\mathrm{U}(0,50)$ \\
\hline$\beta_{\text {FDist }}$ & Coefficient of fire effect (Distance subgroup) & $\mathrm{N}\left(0, \sigma_{\mathrm{FDist}}\right)$ \\
\hline$\sigma_{\text {FDist }}$ & Prior standard deviation for $\beta_{\mathrm{FD} \text { ist }}$ & $\mathrm{U}(0,50)$ \\
\hline$\beta_{\text {FArea }}$ & Coefficient of fire effect (Area subgroup) & $\mathrm{N}\left(0, \sigma_{\text {FArea }}\right)$ \\
\hline$\sigma_{\text {FArea }}$ & Prior standard deviation for $\beta_{\text {FArea }}$ & $\mathrm{U}(0,50)$ \\
\hline$\beta_{\text {Edge }}$ & Coefficient of fire effect (Edge subgroup) & $\mathrm{N}\left(0, \sigma_{\text {Edge }}\right)$ \\
\hline$\sigma_{\text {Edge }}$ & Prior standard deviation for $\beta_{\text {FEdge }}$ & $\mathrm{U}(0,50)$ \\
\hline$\beta_{\text {Precip }}$ & Coefficient of precipitation effect & $\mathrm{N}\left(0, \sigma_{\text {Precip }}\right)$ \\
\hline$\sigma_{\text {Precip }}$ & Prior standard deviation of $\beta_{\text {Precip }}$ & $\mathrm{U}(0,50)$ \\
\hline$\beta_{\text {Interaction }}$ & Coefficient of interaction effect between fire and precipitation & $\mathrm{N}\left(0, \sigma_{\text {Interaction }}\right)$ \\
\hline$\sigma_{\text {Interaction }}$ & Prior standard deviation for $\beta_{\text {Interaction }}$ & $\mathrm{U}(0,50)$ \\
\hline$\zeta_{\text {Lek s }}$ & Random lek effect, for lek s, where $\mathrm{s}=1, \ldots, 1770$ & $\mathrm{~N}\left(0, \sigma_{\mathrm{Lek}}\right)$ \\
\hline$\sigma_{\text {Lek }}$ & Prior standard deviation for $\zeta_{\text {Lek s }}$ & $\mathrm{U}(0,50)$ \\
\hline$\zeta_{\text {Year s }}$ & Random year effect, for year $\mathrm{t}$, where $\mathrm{t}=1985-2013$. & $\mathrm{N}\left(0, \sigma_{\text {Year }}\right)$ \\
\hline$\sigma_{\text {Year }}$ & Year standard deviation of $\zeta_{\text {Year }}$ & $\mathrm{U}(0,50)$ \\
\hline
\end{tabular}


During step 1, within the density-dependence group, we evaluated a lag-Gompertz model against the null model. The DIC was less than that of the null model, so we carried it forward for inclusion in all models within the wildfire and precipitation groups to consistently account for density-dependence. Within the wildfire group, we created three subgroups of covariates to singularly evaluate the effects of: (1) distance to burned perimeter; (2) burned area; and (3) burned edge. Distance to burned perimeter only included distance to acutely affected burned areas (hereinafter, acute distance). Burned area and PA ratio were based on acutely and chronically affected areas at the 5- and 10-km scale. Chronically affected burn and edge (hereinafter, chronic area and chronic edge) included measurements of cumulative area calculated using the different R\&R-based recovery rates (that is, normal, accelerated, decelerated). Within the precipitation group, we used the same criteria to carry-forward the single-best model of seasonal or annual precipitation at the 5- or 10-km scale. Precipitation did not include any subgroups. All wildfire and precipitation covariates were centered and standardized using Z-scores (Zar, 1996) to allow for consistent scales of measurement and improve model convergence. Densitydependence variable represented by lag-Gompertz conversion was already log-transformed.

In step 2, we fit two additive models that combined lag-Gompertz with wildfire and precipitation covariates carried forward from step 1 . We also fit a model that included an interaction between the effects of precipitation and wildfire to test if wildfire effects on population rate of change varied by precipitation. The model with the lowest DIC was chosen for predictive modeling. Multicollinearity among covariates $(\mathrm{r}>|0.65|)$ was not detected among any step 2 models. We followed the suggestions of Kéry (2010) to assess model fit by constructing plots of residuals against predicted values, developing posterior predictive distributions, and calculating Bayesian $p$-values, whereby $p \sim 0.5$ indicates good fit. We reduced the number of posterior iterations to 1,000 owing to the large number of parameters required for calculating residual plots, and increased the burn-in to 20,000 iterations to facilitate better convergence for more complex models. To interpret covariate effects, we report the median parameter estimates of the posterior distribution and 95 percent credible intervals (CI; that is, 2.5 and 97.5 percentiles of the posterior distribution that represent the lower and upper bounds, respectively, of the $\mathrm{CI}$ ).

\section{Modeling Cumulative Burned Area in Relation to Leks}

A Bayesian linear model was used to describe increases in cumulative burned area through time from 1984 to 2014, and resulting posterior distributions were then used to forecast future changes in cumulative burned area out to 30 years. We selected the burned area covariate from a subgroup of models formed to test different combinations of spatial scale (that is, 5 and $10 \mathrm{~km}$ from lek) and acute and chronic R\&R-based recovery times (that is, accelerated, normal, decelerated) that best described variation in annual population change (described in step 1 above), and regressed it against year as a continuous fixed effect. Separate models were run for each R\&R index class to evaluate changes in burned area near leks over time relative to spatially explicit predictions of R\&R, and then each model was compared to a null (intercept only) model using DIC. Parameter estimates were derived from distributions of uninformative prior probabilities (table 4). 
Table 4. Description of parameters in the model for estimating change in cumulative fire area within 5-km of leks in the Great Basin from 1984 to 2013.

[All parameters are estimated using Bayesian techniques assuming minimal prior information, using Uniform (U) or Normal (N) prior distributions, and include coefficients of trend $\left(\beta_{Y e a r}\right)$, and standard deviations $(\sigma)$. Cumulative fire area is modeled as $\beta_{\text {Year }}$ Year]

\begin{tabular}{lll}
\hline Symbol & \multicolumn{1}{c}{ Description } & Prior distribution \\
\hline$\sigma_{\mathrm{r}}$ & Standard deviation for annual rate of recovery & $\mathrm{U}(0,1.5 e 7)$ \\
$\beta_{\text {Year }}$ & Mean effect for year & $\mathrm{N}\left(0, \sigma_{\text {Year }}\right)$ \\
$\sigma_{\text {Year }}$ & Standard deviation for year effect & $\mathrm{U}(0,1.5 e 7)$ \\
\hline
\end{tabular}

\section{Management Scenarios}

Indices of habitat suitability and animal abundance provide useful proxy-based measures for use in adaptive management (Coates and others, 2014; Stephens and others, 2015). Doherty and others (U.S. Fish and Wildlife Service, written commun., 2015) derived a range-wide population index model for sage-grouse using such indices that incorporated sage-grouse habitat suitability generated from Random Forest models (Evans and others, 2011), and spatially explicit abundance measures based on fixed kernel density functions on lek locations. The kernels were generated using two bandwidth distances representing the majority of breeding habitat in relation to leks $(6.4 \mathrm{~km})$ and seasonal movements $(18.0$ $\mathrm{km})$. We evaluated relationships between abundance indices and the overall population index model to demarcate areas that are the most meaningful to sage-grouse populations. Specifically, we clipped the range-wide continuous population index layer to the Great Basin study extent (buffered by $10 \mathrm{~km}$ ), and extracted isopleths for the percentage of cumulative volume under the layer at 5 percent increments starting at 65 percent. Following Doherty and others (2015), we overlaid locations of active leks (that is, greater than two males observed in greater than two of the previous 5 years) and pending leks (that is, greater than two males observed only once over the previous 5 years) on the clipped layer and extracted the maximum lek count from 2009 to 2014 as an index of population size within each isopleth class. Active and pending leks $(n=1,896)$ had at least one count greater than two males during the time interval. For each successive isopleth class, we calculated the ratio of the cumulative increase in population size to cumulative area added to the population index model, and rescaled the ratio between zero and 100. To determine a cut-point for the population index model that represented where sagegrouse density was most concentrated, we fit an exponential regression between population index model isopleth values and the cumulative ratio of increasing population size to area added, and determined where the slope of the line equaled 1.0 (Vander Wal and Rodgers, 2012). The slope equaled 1.0 at the 76.4 percent isopleth, which when rounded to 75 percent was used to demarcate example 'core areas' (fig. 3). To inform decisions of conservation actions by State and Federal agencies, we ran simulations to examine how targeted 25, 75, and 99 percent reductions in the rate (trend) of annual cumulative burned area in these core areas might alter sage-grouse population trajectories over the next 30 years. Posterior distributions are reported. 


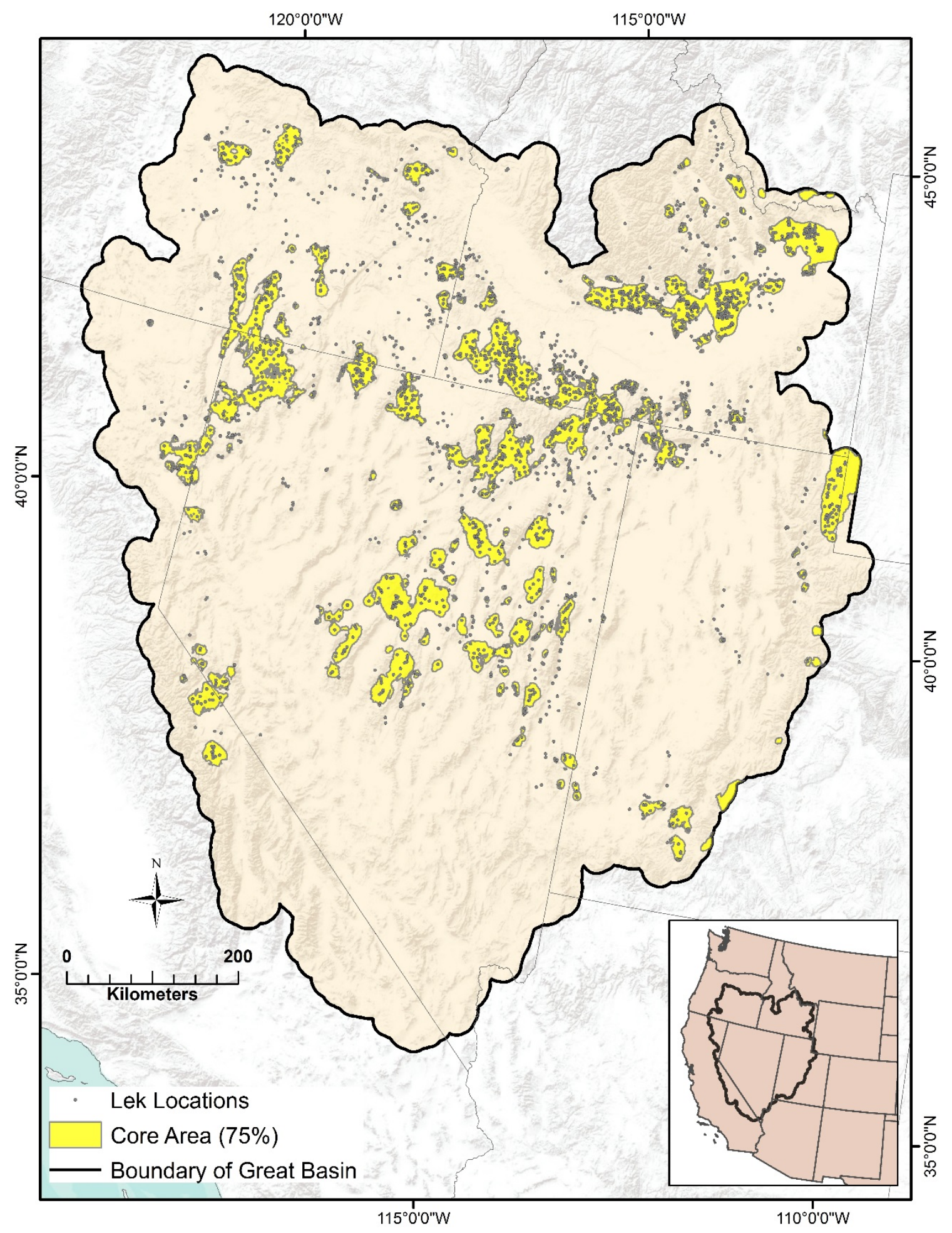

Figure 3. Map of estimated sage-grouse core areas and associated distribution of breeding leks in the Great Basin. 


\section{Results of Wildfire Effects on Sage-Grouse}

\section{General 30-Year Wildfire Patterns across the Great Basin}

The MTBS-based dataset used for wildfire modeling comprised a pool of 3,102 fire perimeters in the Great Basin from 1984 to 2013. Although substantial variation existed among years, total burned area increased by an average of $153 \mathrm{~km}^{2} / \mathrm{yr}$. Some variation could be explained by annual precipitation relative to the 30 -year average of precipitation $(32.3 \mathrm{~cm})$, where total burned area was greater, on average, during years of below-average precipitation (524,134 ha burned per year) compared to those years of above average precipitation (239,873 ha burned per year) (fig. 4). Additional variation could be explained by R\&R index class burned, whereby total burned area tended to be higher for wildfires burning over land cover with low underlying R\&R compared to those with moderate and high underlying R\&R (fig. 5). When evaluated on a cumulative basis that allowed for normal recovery (based on results below) a total of $13,173 \mathrm{~km}^{2}$ of land cover with low underlying R\&R burned from 1984 to 2013 compared to $6,390 \mathrm{~km}^{2}$ of moderate and $4,349 \mathrm{~km}^{2}$ of high underlying R\&R during the same period (fig. 6). We assumed all land cover types within these generalized $R \& R$ classes recovered at the same R\&R-specific rates as sagebrush for illustrative purposes, and because this calculation is across the Great Basin and our analysis is in relation to $5 \mathrm{~km}$ of leks, this trend was not used for model projections.

\section{Wildfire and Precipitation Effects on Annual Population Rate of Change}

After subjecting all lek count data to QA/QC screening, the final dataset used to model wildfire and precipitation effects on annual population rate of change comprised of 1,770 leks across the Great Basin (table 5). Idaho and Nevada had the most leks (69.8 percent of total) and California had the least (4.6 percent of total). Average number of males per lek was less than 30. Posterior distributions of parameters were then generated from 14,834 estimates of instantaneous population rate of change $(r)$ derived from consecutive pairs of lek counts.

For step 1, Gompertz type density-dependence with a 1-year lag (lag-Gompertz) explained more variance in annual population growth than the null (random effects only), and was thus carried forward to all models with wildfire and precipitation covariates (table 6). Within the wildfire covariate group, the model with distance to burned perimeter had a lower DIC compared to the random intercept model $\left(\Delta \mathrm{DIC}_{\text {null }}<-72.0\right)$ and the lag-Gompertz only model $\left(\Delta \mathrm{DIC} \mathrm{DD}_{\mathrm{DD}}<-8.0\right)$, so this covariate was carried forward to step 2 . Within the burned area subgroup, chronic area with normal recovery rate within $5 \mathrm{~km}$ of a lek had the lowest DIC compared to the random intercept model, and was $6.8 \Delta \mathrm{DIC}_{\mathrm{DD}}$ units better than the lag-Gompertz only model, so this covariate was carried forward to step 2. 


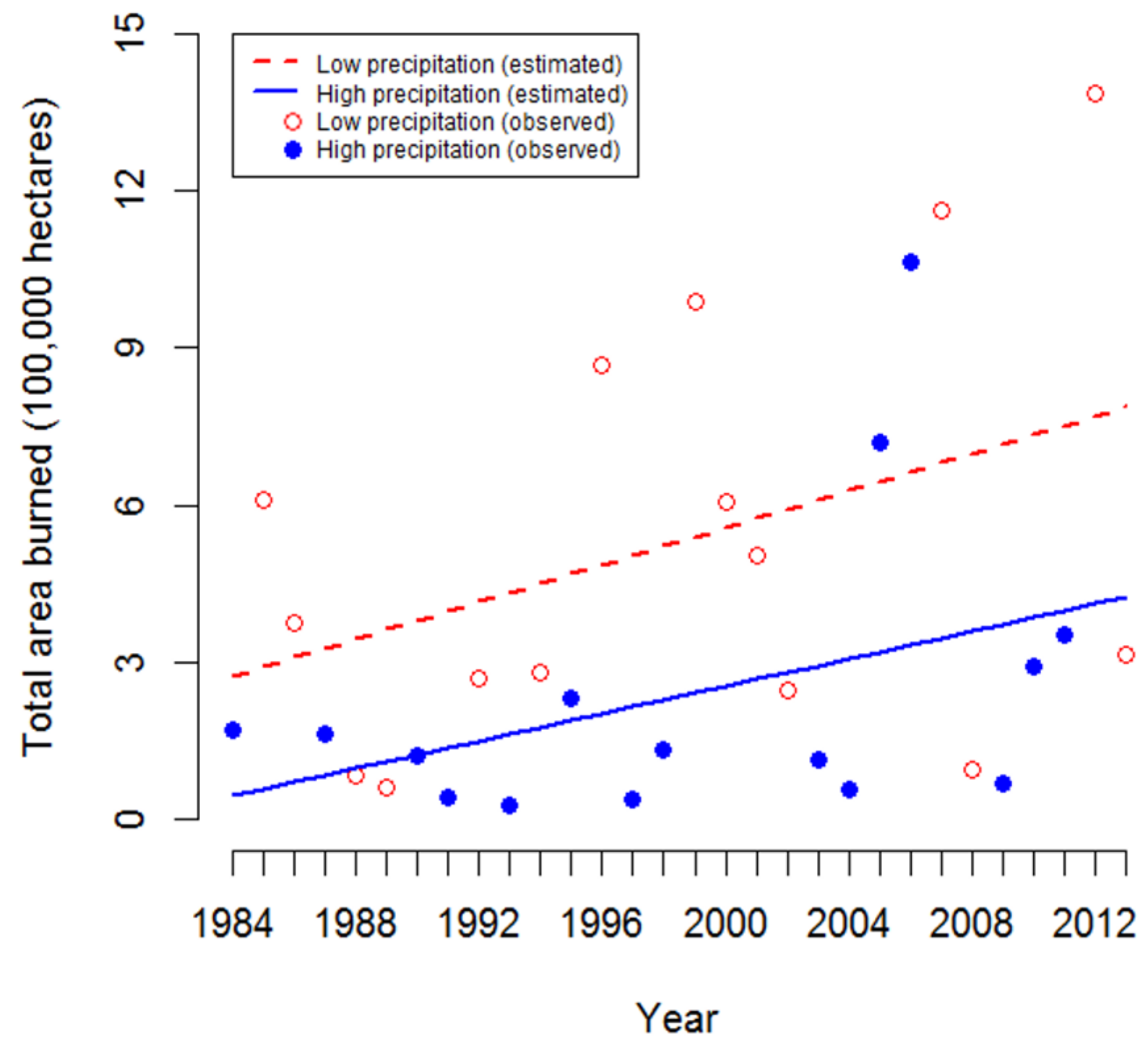

Figure 4. Relation between total burned area (acute) and time by low $(<32.3 \mathrm{~cm})$ and high $(>32.3 \mathrm{~cm})$ precipitation years in the Great Basin from 1984 to 2013. 


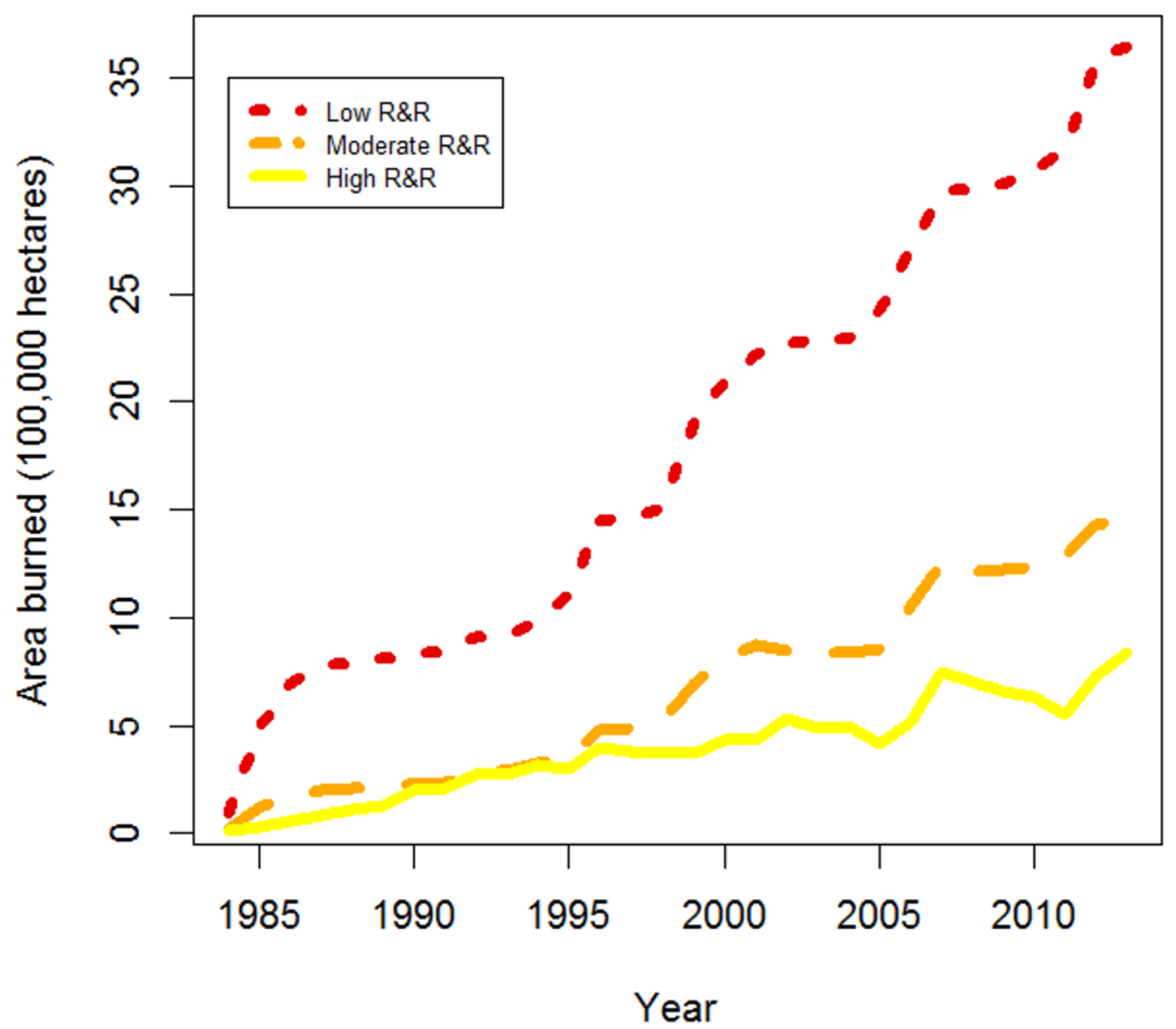

Figure 5. Increases in burned area (cumulative) by R\&R index class across the Great Basin from 1984 to 2013. 


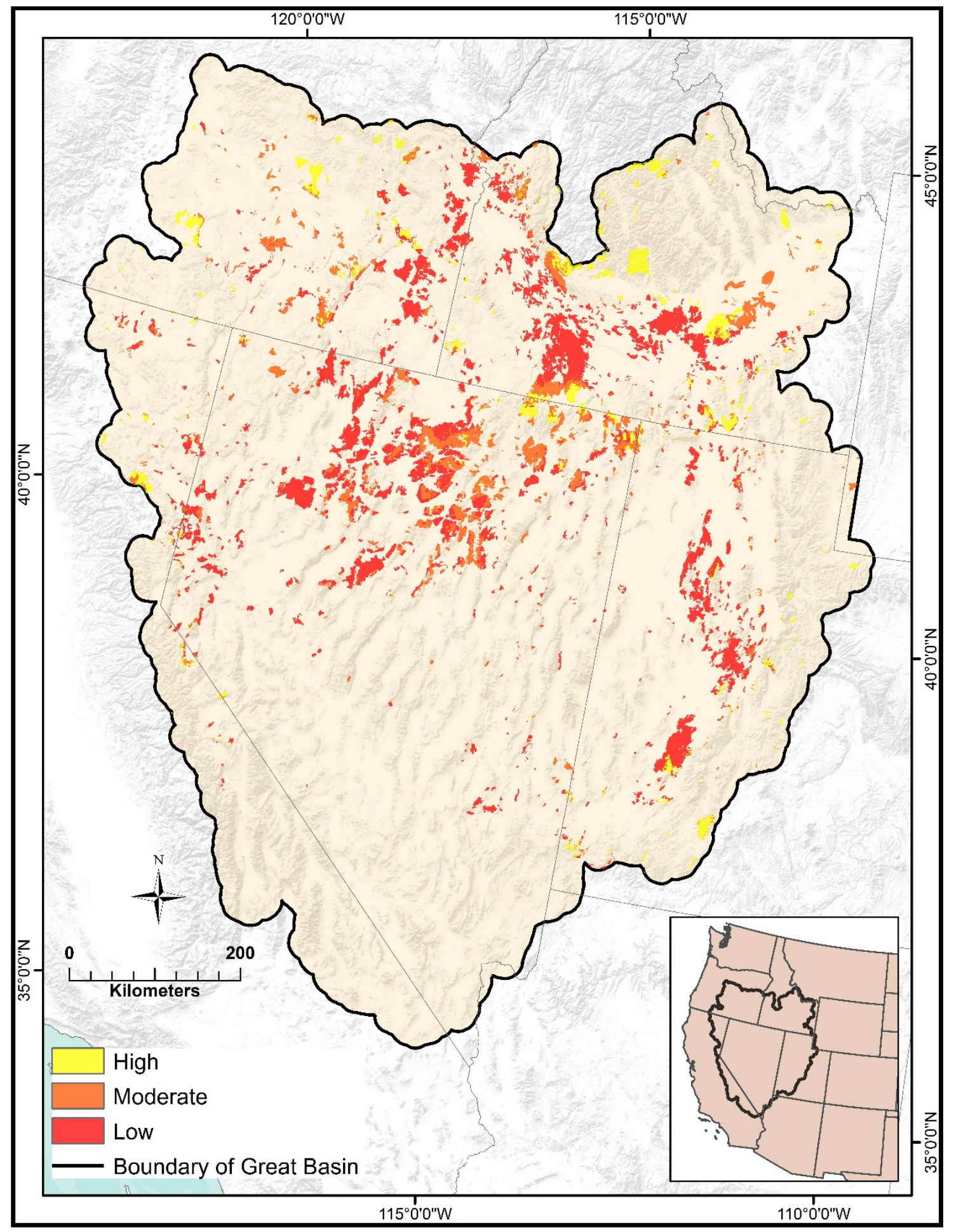

Figure 6. Map of cumulative burned area by R\&R index class across the Great Basin as of 2013. 
Table 5. Descriptive statistics for number of leks counted per state, male lek attendance, corresponding number of estimates of annual population rate of change $(\lambda)$ used as response variables in Bayesian modeling of wildfire, precipitation, and density effects on sage-grouse in the Great Basin from 1985 to 2013.

\begin{tabular}{l|c|cccc|ccccc}
\hline \multirow{2}{*}{ State } & \multirow{2}{*}{$\begin{array}{c}\text { Number } \\
\text { of leks }\end{array}$} & \multicolumn{4}{c}{ Number of males per lek } & \multicolumn{5}{c}{ Samples (estimated $r$ ) per lek } \\
\cline { 3 - 11 } & Average & SD & Min & Max & Average & SD & Min & Max & Total \\
\hline Idaho & 695 & 14.4 & 13.5 & 0.2 & 83.7 & 8.5 & 7.4 & 1 & 29 & 5,909 \\
Nevada & 540 & 16.5 & 14.2 & 0.5 & 94.9 & 6.3 & 6.4 & 1 & 29 & 3,413 \\
Oregon & 288 & 15.7 & 15.6 & 0.4 & 96.1 & 9.5 & 7.8 & 1 & 29 & 2,738 \\
Utah & 166 & 16.4 & 15.7 & 0.3 & 106.2 & 10.8 & 8.2 & 1 & 29 & 1,797 \\
California & 81 & 22.0 & 27.2 & 1.6 & 135.7 & 12.1 & 9.7 & 1 & 29 & 977 \\
\hline All States & 1,770 & 15.8 & 15.3 & 0.2 & 135.7 & 8.4 & 7.5 & 1 & 29 & 14,834 \\
\hline
\end{tabular}

Table 6. Ranking and selection of models formulated to identify the best combination of wildfire, precipitation, and density predictor variables influencing 30-year patterns of sage-grouse population growth across the Great Basin based on change in Deviance Information Criterion $(\Delta \mathrm{DIC})$.

[ $\triangle \mathrm{DIC}_{\text {Group }}$ is defined as DIC minus the minimum DIC value within the same group or subgroup, and is used to compare models within each group or subgroup; $\triangle \mathrm{DIC} \mathrm{DD}_{\mathrm{DD}}$ is defined as DIC minus the DIC of the lagged-Gompertz-only model, and is used to compare each model to the Gompertz (one year lag) density-dependent model; $\triangle \mathrm{DIC}_{\text {null }}$ is defined as DIC minus the DIC of the random-effects only model]

\begin{tabular}{|c|c|c|c|c|c|c|c|}
\hline Step & Group & Subgroup & Model & DIC & $\Delta \mathrm{DIC}_{\text {Group }}$ & $\Delta \mathrm{DI} \mathrm{C}_{\mathrm{DD}}$ & $\Delta \mathrm{DIC}_{\text {null }}$ \\
\hline \multirow[t]{19}{*}{1} & Density- & NA & Gompertz (one year lag) & 56469.64 & 0.00 & 0.00 & -63.81 \\
\hline & & & Null & 56533.45 & 63.81 & 63.81 & 0.00 \\
\hline & Wildfire & Distance & Distance & 56461.19 & 0.00 & -8.45 & -72.26 \\
\hline & & Area & Chronic area, normal, $5 \mathrm{~km}$ & 56462.79 & 0.00 & -6.85 & -70.66 \\
\hline & & & Chronic area, accelerated, $5 \mathrm{~km}$ & 56463.24 & 0.45 & -6.40 & -70.21 \\
\hline & & & Chronic area, normal, $10 \mathrm{~km}$ & 56463.33 & 0.54 & -6.31 & -70.12 \\
\hline & & & Chronic area, accelerated, $10 \mathrm{~km}$ & 56464.92 & 2.13 & -4.72 & -68.53 \\
\hline & & & Chronic area, decelerated, $5 \mathrm{~km}$ & 56464.98 & 2.19 & -4.66 & -68.47 \\
\hline & & & Chronic area, decelerated, $10 \mathrm{~km}$ & 56465.99 & 3.20 & -3.65 & -67.46 \\
\hline & & & Acute area, $5 \mathrm{~km}$ & 56472.51 & 9.72 & 2.87 & -60.94 \\
\hline & & & Acute area, $10 \mathrm{~km}$ & 56473.57 & 10.78 & 3.93 & -59.88 \\
\hline & & Edge & Chronic perimeter:area, decelerated, $10 \mathrm{~km}$ & 56469.78 & 0.00 & 0.14 & -63.67 \\
\hline & & & Chronic perimeter:area, decelerated, $5 \mathrm{~km}$ & 56470.95 & 1.17 & 1.31 & -62.50 \\
\hline & & & Chronic perimeter:area, accelerated, $10 \mathrm{~km}$ & 56471.58 & 1.80 & 1.94 & -61.87 \\
\hline & & & Chronic perimeter:area, normal, $10 \mathrm{~km}$ & 56472.28 & 2.50 & 2.64 & -61.17 \\
\hline & & & Acute perimeter:area, $10 \mathrm{~km}$ & 56472.76 & 2.98 & 3.12 & -60.69 \\
\hline & & & Chronic perimeter:area, accelerated, $5 \mathrm{~km}$ & 56473.43 & 3.65 & 3.79 & -60.02 \\
\hline & & & Chronic perimeter:area, normal, $5 \mathrm{~km}$ & 56473.67 & 3.89 & 4.03 & -59.78 \\
\hline & & & Acute perimeter: area, $5 \mathrm{~km}$ & 56473.83 & 4.05 & 4.19 & -59.62 \\
\hline
\end{tabular}




\begin{tabular}{|c|c|c|c|c|c|c|c|}
\hline Step & Group & Subgroup & Model & DIC & $\Delta \mathrm{DI} \mathbf{C}_{\text {Group }}$ & $\Delta \mathrm{DIC}_{\mathrm{DD}}$ & $\Delta \mathrm{DIC}_{\text {null }}$ \\
\hline & \multirow[t]{16}{*}{ Precipitation } & \multirow[t]{16}{*}{ NA } & Spr-Sum-Fall, 10 km & 56467.06 & 0.00 & -2.58 & -66.39 \\
\hline & & & Spr-Sum, 10 km & 56468.81 & 1.75 & -0.83 & -64.64 \\
\hline & & & Sum, $5 \mathrm{~km}$ & 56468.84 & 1.78 & -0.80 & -64.61 \\
\hline & & & Annual, $1 \mathrm{~km}$ & 56468.93 & 1.87 & -0.71 & -64.52 \\
\hline & & & Spr-Sum-Fall, 5 km & 56469.11 & 2.05 & -0.53 & -64.34 \\
\hline & & & Sum, $10 \mathrm{~km}$ & 56469.12 & 2.06 & -0.52 & -64.33 \\
\hline & & & Fall, $10 \mathrm{~km}$ & 56469.30 & 2.24 & -0.34 & -64.15 \\
\hline & & & $\mathrm{Spr}, 10 \mathrm{~km}$ & 56469.91 & 2.85 & 0.27 & -63.54 \\
\hline & & & Win-Spr-Sum, 10 km & 56470.04 & 2.98 & 0.40 & -63.41 \\
\hline & & & Spr-Sum, 5 km & 56470.73 & 3.67 & 1.09 & -62.72 \\
\hline & & & Annual, $5 \mathrm{~km}$ & 56470.79 & 3.73 & 1.15 & -62.66 \\
\hline & & & $\mathrm{Spr}, 5 \mathrm{~km}$ & 56471.30 & 4.24 & 1.66 & -62.15 \\
\hline & & & Fall, $5 \mathrm{~km}$ & 56471.92 & 4.86 & 2.28 & -61.53 \\
\hline & & & Win-Spr-Sum, 5 km & 56472.02 & 4.96 & 2.38 & -61.43 \\
\hline & & & Win, $10 \mathrm{~km}$ & 56472.75 & 5.69 & 3.11 & -60.70 \\
\hline & & & Win, $5 \mathrm{~km}$ & 56473.42 & 6.36 & 3.78 & -60.03 \\
\hline \multirow[t]{3}{*}{2} & $\begin{array}{l}\text { Combined } \\
\text { (Interaction) }\end{array}$ & NA & $\begin{array}{l}\text { Acute distance }+ \text { Chronic area, } 5 \mathrm{~km} * \mathrm{Spr}- \\
\text { Sum-Fall, } 10 \mathrm{~km}+\text { Gompertz }(1-\text { year lag })\end{array}$ & 56457.16 & 0.00 & NA & NA \\
\hline & $\begin{array}{l}\text { Combined } \\
\text { (Additive) }\end{array}$ & NA & $\begin{array}{l}\text { Acute distance }+ \text { Chronic area, } 5 \mathrm{~km}+ \\
\text { Gompertz (1-year lag) }\end{array}$ & 56458.59 & 1.43 & NA & NA \\
\hline & & & $\begin{array}{l}\text { Acute distance }+ \text { Chronic area, } 5 \mathrm{~km}+\text { Spr- } \\
\text { Sum-Fall, } 10 \mathrm{~km}+\text { Gompertz }(1 \text {-year lag) }\end{array}$ & 56458.90 & 1.74 & NA & NA \\
\hline
\end{tabular}


Competing evidence $\left(\triangle \mathrm{DIC} \mathrm{C}_{\text {group }}<2.0\right)$ existed for chronic area with normal and accelerated recovery rate within 10 and $5 \mathrm{~km}$ of a lek, respectively, but we only carried forward the single best model to limit complexity of step 2. Notably, all models of acute burned area had a poorer DIC than the lag-Gompertz only model $\left(\Delta \mathrm{DIC} \mathrm{CD}_{\mathrm{DD}}>0.0\right)$. Within the burned edge subgroup, no models were supported by the data better than the lag-Gompertz only model. Hence, no PA ratio covariates were carried forward to step 2. Finally, within the precipitation group, the model with precipitation within $10 \mathrm{~km}$ of a lek during spring, summer, and fall had the lowest DIC, and improved significantly on the lagGompertz only model $\left(\triangle \mathrm{DIC} \mathrm{DD}_{\mathrm{DD}}<-2\right)$, and this covariate was carried forward to step 2 . No other precipitation group models satisfied the rule of $\Delta \mathrm{DIC}_{\mathrm{DD}}<-2.0$, so no other precipitation covariates were carried forward. Convergence criteria was met for all models (R-hat $<1.1$ ).

For step 2, main effects models containing additive effects of density-dependence, wildfire, and precipitation explained less variation in $\lambda$ compared to the model containing interaction effects between wildfire and precipitation (table 6). The equation for the final model including all carried-forward variables took the form:

$$
\begin{gathered}
\log \left(\lambda_{t}\right)=\beta_{0}+\beta_{\mathrm{DD}} \log \left(N_{t-1}\right)+\beta_{\mathrm{FDist}} X_{\mathrm{FDist}}+\beta_{\mathrm{FArea}} X_{\mathrm{FArea}}+ \\
\beta_{\text {Precip }} X_{\text {Precip }}+\beta_{\text {Interaction }} X_{\text {FArea }} X_{\text {Precip }}+\zeta_{\text {Lek }}+\zeta_{\text {Year }}
\end{gathered}
$$

where $\beta$ s represent coefficients for intercept (0), lag-Gompertz density-dependence (DD), distance to perimeter burned (FDist), cumulative burned area (FArea), and seasonal precipitation (Precip; spring through fall), $\zeta \mathrm{s}$ represent random effects for lek and year. Descriptions are provided in table 3 . Fit of the final model was excellent (Bayesian $P=0.496$ ), and indicated that effects of wildfire varied inconsistently across the range of precipitation while accounting for density-dependence. Posterior probability distributions of the parameters for wildfire effects indicated that variation in population rate of change was positively related to distance away from the burned perimeter and negatively related to cumulative burned area with normal recovery rate within $5 \mathrm{~km}$ of a lek. On average, rate of change increased by approximately 1.1 percent (posterior median $=0.011,95$-percent $\mathrm{CI}=0.007-0.015$ ) with every $10 \mathrm{~km}$ increase in distance to burned perimeter (fig. 7$)$, and decreased by 2.1 percent $(0.021,95$ percent $\mathrm{CI}=0.012-0.031$ ) with every $10 \mathrm{~km}^{2}$ increase in cumulative burned area (fig. 8 ). Interactive effects between cumulative wildfire and total precipitation during spring, summer, and fall indicated intriguing and complex patterns (fig. 9). Increasing precipitation correlated with increasing population size, whereby $\lambda$ was predicted to exceed 1.0 during years of above-average precipitation if cumulative burned area was not too large. However, the positive effect of precipitation on population growth decreased as cumulative burned area increased, whereby $\lambda$ was predicted to be below 1.0 during years with high precipitation at leks associated with relatively large amounts of cumulative burned area. 


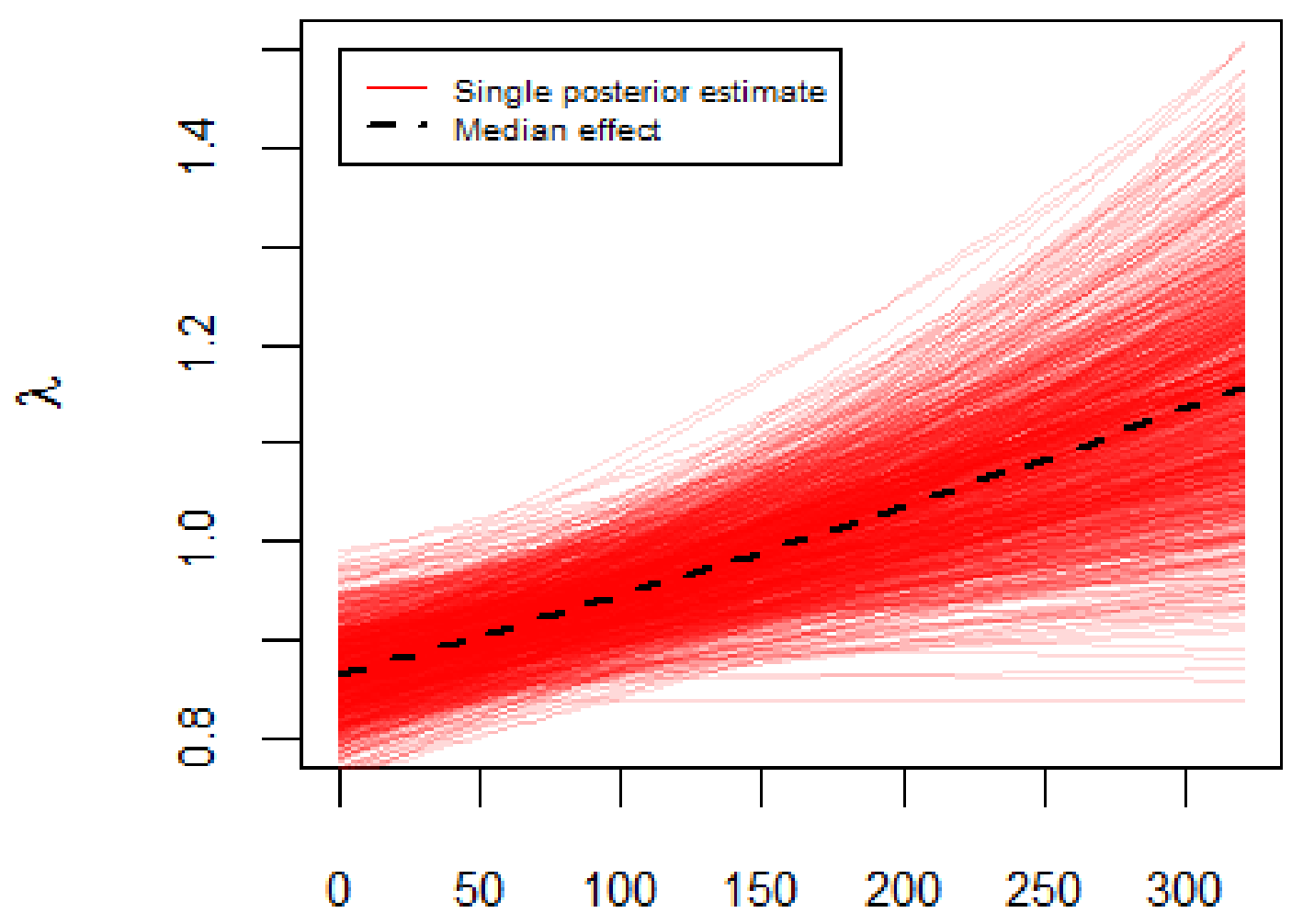

\section{Distance to burn (km)}

Figure 7. Effect of distance to burn perimeter on the annual population rate of change $(\lambda)$ of sage-grouse across the Great Basin from 1985 to 2014. Ten thousand samples from the posterior distributions of model parameters were used to represent the range of uncertainty in this relationship. 


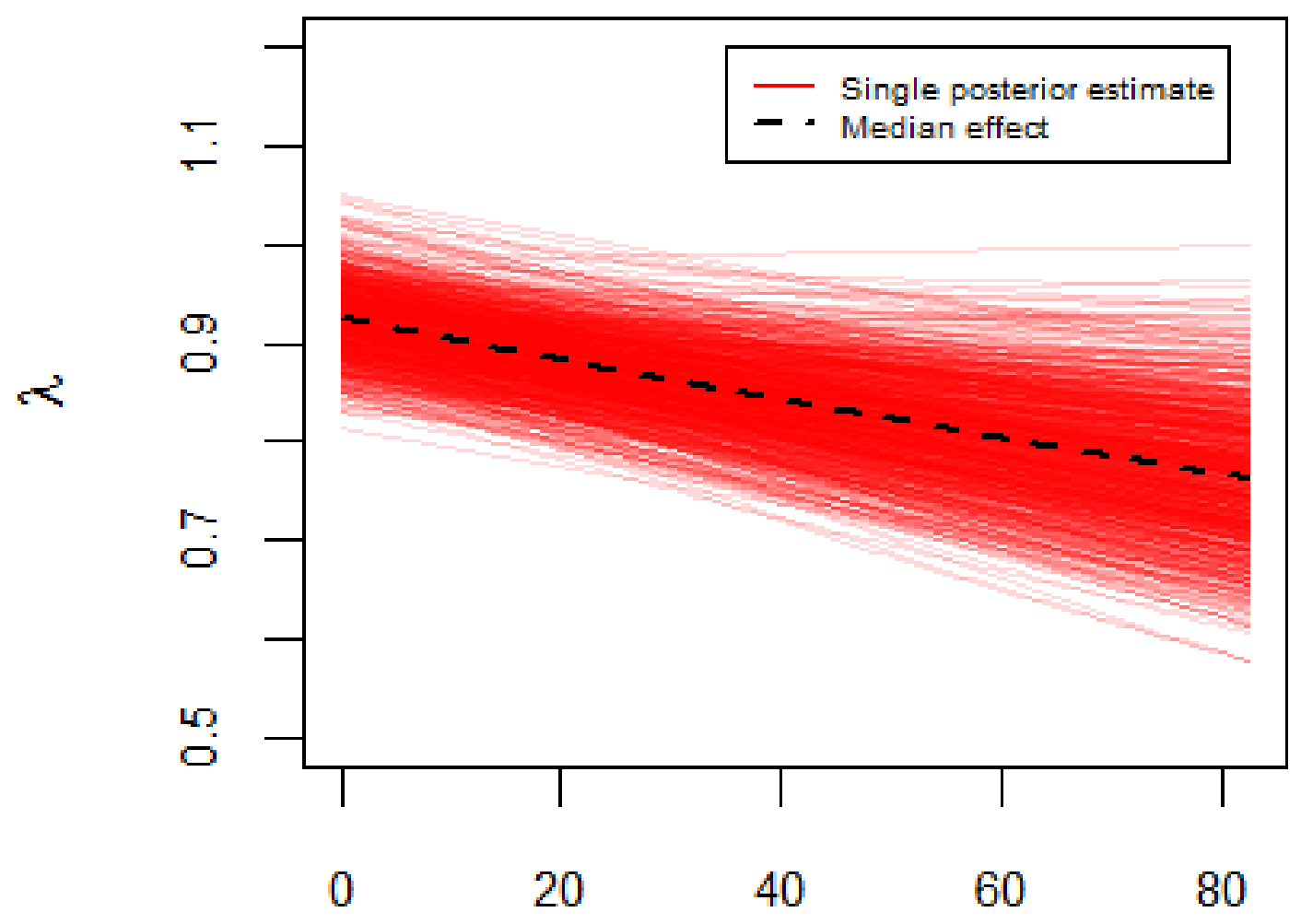

Cumulative burned area (square-km)

Figure 8. Effect of cumulative burned area (square- $\mathrm{km}$ ) on the annual population rate of change $(\lambda)$ of sage-grouse across the Great Basin from 1985 to 2014. Ten thousand samples from the posterior distributions of model parameters were used to represent the range of uncertainty in this relationship. 


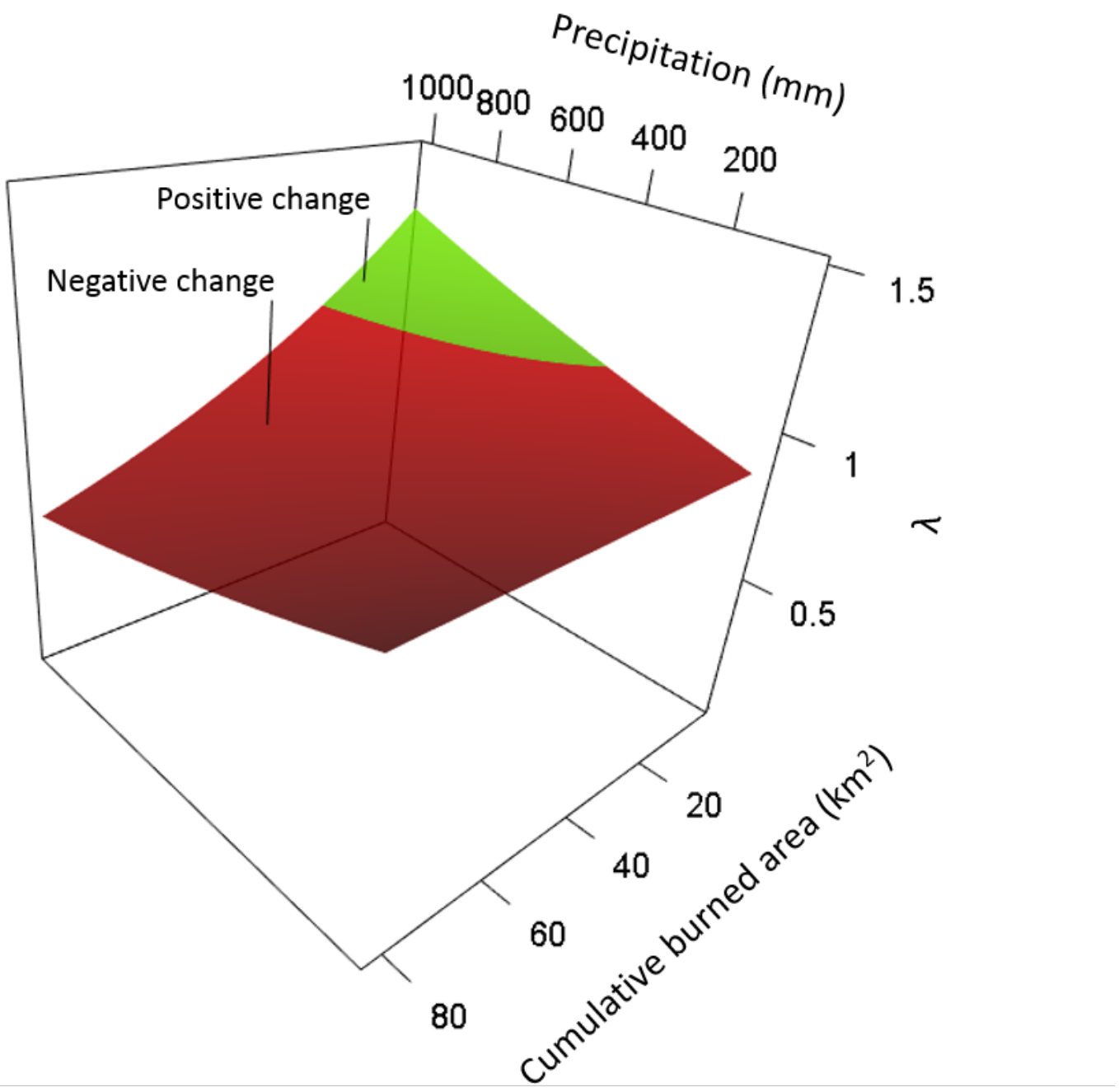

Figure 9. Three-dimensional display of the interaction effects between precipitation (spring through fall) and cumulative burned area on population rate of change $(\lambda)$ of sage-grouse in the Great Basin from 1985 to 2014. 


\section{Patterns of Cumulative Burned Area and Recovery Near Leks}

Based on results from the burned area subgroup test in step 1 above, we modeled cumulative burned area per year within $5 \mathrm{~km}$ of leks using the normal burn recovery rate to describe past and predict future changes in the amount of burned areas, which explained more variation than the null model $(\triangle \mathrm{DIC}=6.85)$ and adequately converged $(\mathrm{R}-h a t \leq 1.1)$. The inter-annual trend estimate (median value of posterior probability distribution) indicated that $3.4 \mathrm{~km}^{2}(0.4$ percent $)$ per lek burned annually when averaged across all three R\&R classes (fig. 10). When expressed as cumulative averages for the burned proportional area within $5 \mathrm{~km}$ of a lek for each resilience and resistance index classes: high R\&R burned at 0.36 percent per year (95-percent $\mathrm{CI}=0.0034-0.0039)$, moderate $\mathrm{R} \& \mathrm{R}$ burned at 0.34 percent per year (95-percent $\mathrm{CI}=0.0031-0.0037$ percent), and low R\&R burned at 0.53 percent (95-percent CI $=0.0050-0.0056$; fig. 10). By 2013, an average of 89.1, 89.7, and 84.2 percent of unburned area with high, moderate, and low R\&R, respectively, remained within $5 \mathrm{~km}$ of a lek.

\section{0-Year Predictions of Cumulative Burned Area and Sage-Grouse Population Persistence}

We estimated future cumulative burned area based on normal recovery rate for each R\&R class by extracting 30,000 samples from the posterior probability distribution for area burn rate and extrapolating future cumulative burned area over 30 more years. By 2044, an average of 77.8, 79.1, and 67.8 percent of unburned area with high, moderate, and low R\&R, respectively, was projected to remain within $5 \mathrm{~km}$ of a lek (fig. 10). We then took each sample of the posterior probability distribution for the projected cumulative burned area for each year, and multiplied it by the effect of cumulative burned area on annual population $\lambda$ (derived from step 2) to project proportional changes in population size separately by R\&R index class over the next 30 years. Because the effect of cumulative burned area was confounded by the interaction with precipitation, we generated projections under normal (50th percentile), below-average (25th percentile), and above-average ( 75 th percentile) levels of precipitation from spring through fall. We assumed a stable population $(\lambda=1.0)$ at the start of projections in order to better mimic environmental conditions facing sage-grouse in the absence of wildfire. Starting population size for projections was based on the mean of the 2014 lek counts within each R\&R class, and subsequent annual changes in population size were expressed as a proportion of the population in 2014.

Sage-grouse populations under normal precipitation conditions declined steadily, resulting in 48, 52 , and 30 percent of grouse in high, moderate, and low R\&R leks, respectively, projected to remain by 2044 according to the 50th percentile parameter (median) of the posterior probability distribution (fig. 11A). Sage-grouse populations declined more sharply under below-average precipitation conditions, for which 36, 38, and 22 percent of grouse in high, moderate, and low R\&R leks, respectively, were projected to remain by 2044 on a median basis (fig. 11B). In contrast, sage-grouse populations in high and moderate R\&R leks remained stable under above-average precipitation conditions through approximately 2025 on a median basis, and some upper percentile distributions showed some population growth. However, high and moderate R\&R leks began to decline after 2025, and only 67 and 71 percent, respectively, remained by 2044. Population decline was invariant to higher precipitation for low R\&R leks, and only 40 percent remained by 2044 (fig. 11C). 


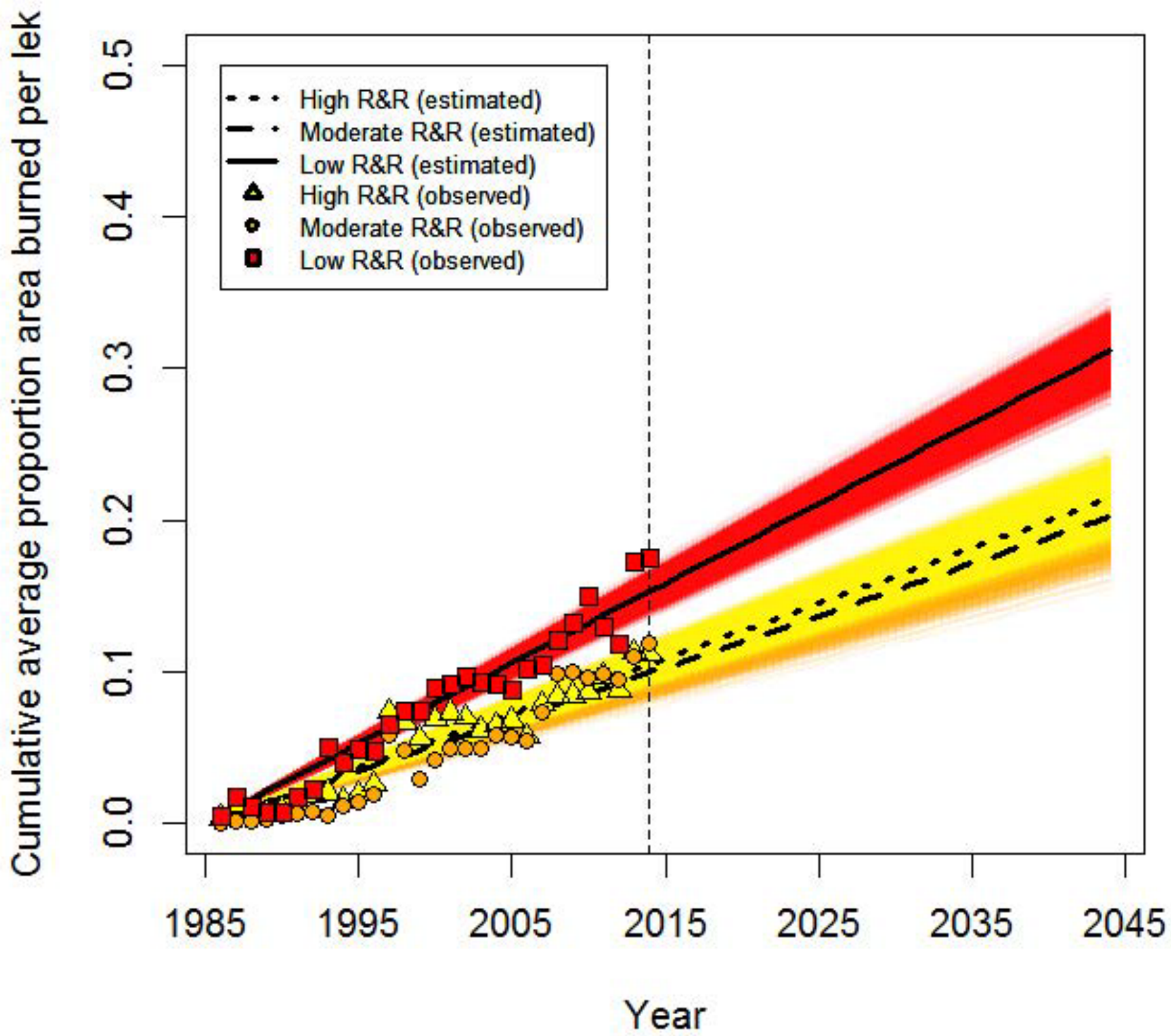

Figure 10. Observed and predicted changes in cumulative burned area over time by R\&R class. Y-axis values represent the average proportion of a $5 \mathrm{~km}$ circular lek buffer. 

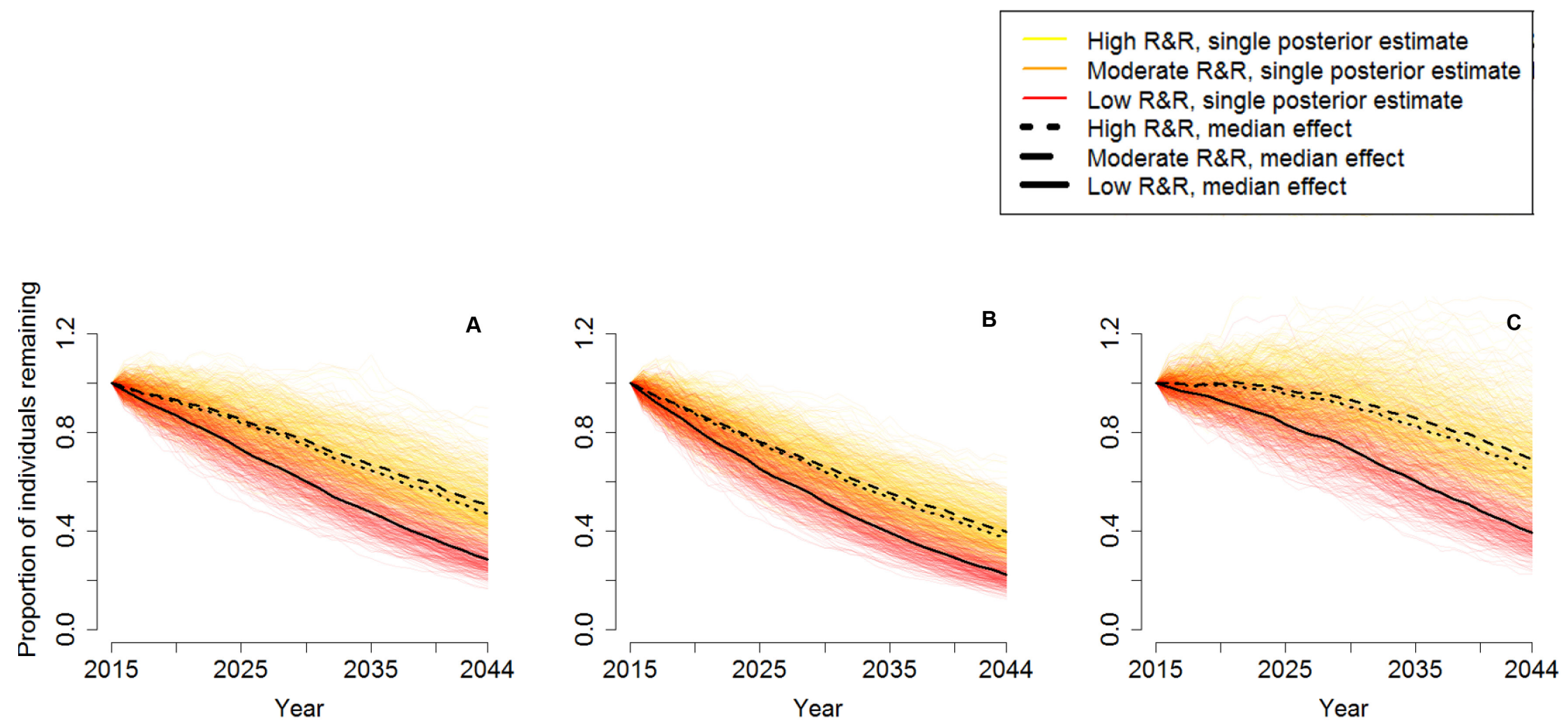

Figure 11. Thirty year predictions for proportion of sage-grouse populations remaining in the Great Basin given modeled effects of cumulative fire on rates of change under projected median (50th percentile; A), low (25th percentile; B), and high (75th percentile; C) amounts of precipitation during spring, summer, and fall. 


\section{Management Scenarios}

Slowing forecasted population declines of Great Basin sage-grouse over the next 30 years may depend on intensity of fire suppression efforts in population 'core areas' and long-term patterns of precipitation (fig. 12). On a median basis, based on our simulations, reducing the rate of annual cumulative burned area by 25 percent in defined 'core areas' under all three modeled precipitation conditions did little to prevent population declines, and trajectories tracked those outside core areas where models allowed wildfires to continue to burn at the original modeled rate. However, reducing the cumulative burned area by 75 percent substantially slowed the rate of population decline under belowaverage precipitation conditions, stabilized population growth under normal precipitation conditions, and resulted in population growth under above-average precipitation conditions. Near complete fire suppression (99 percent) in core areas resulted in slightly increased population growth under all precipitation conditions on a median basis, especially for normal and above-average precipitation.

$25 \%$
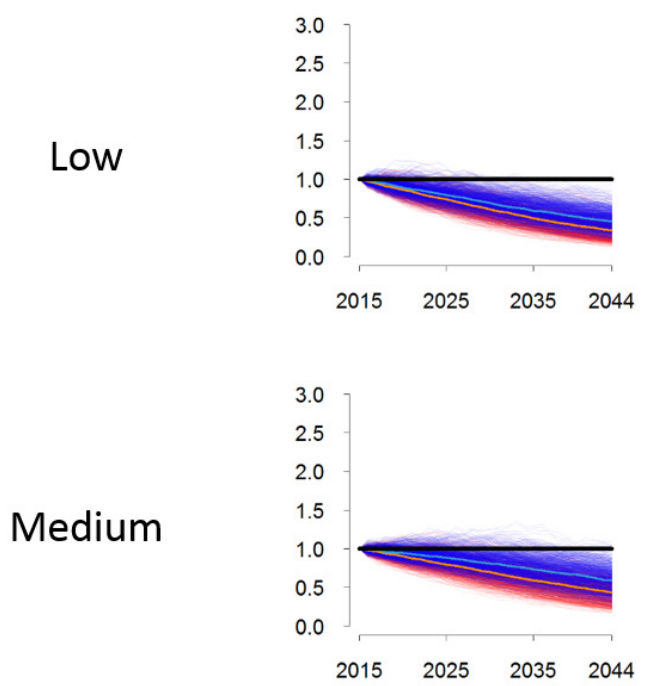

High

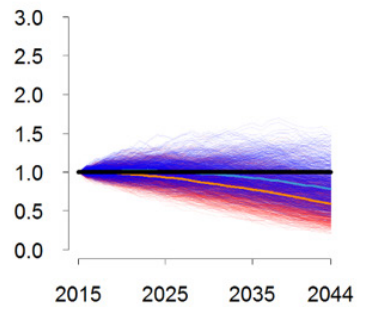

$75 \%$
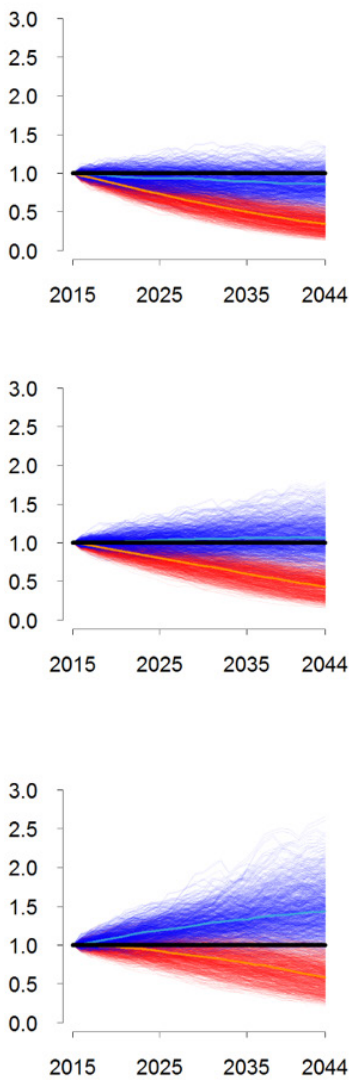

$99 \%$
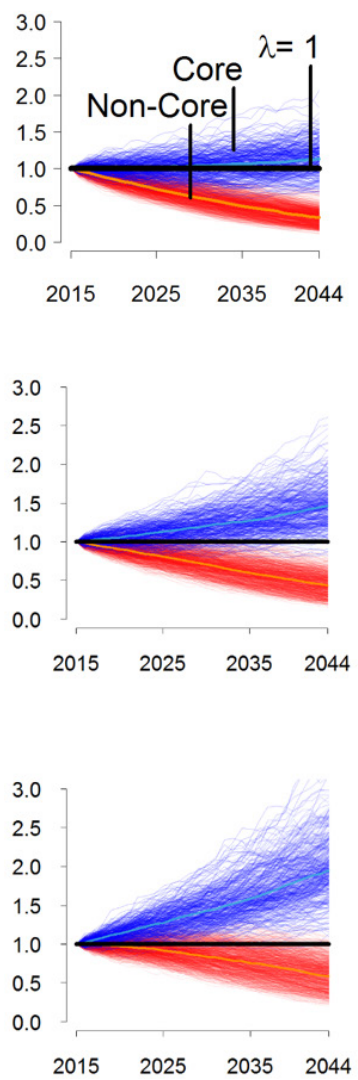

Figure 12. Examples illustrating projected sage-grouse population rate of change $(\lambda)$ over the next 30 years under example management scenarios of 25,75 , and 99 percent reductions in annual average cumulative burned area within $5 \mathrm{~km}$ of lek sites under low, median, and high amounts of precipitation. Solid black line indicates stable population growth $(\lambda=1.0)$. 


\section{Interpretation and Conclusions}

We quantified relatively long-term effects of wildfire and precipitation on sage-grouse population growth across the Great Basin, a significant proportion of the species range. Our results indicate that wildfire has persistently and negatively impacted sage-grouse population growth over the past three decades. Although wildfire is a natural process in sagebrush ecosystems, burn frequency and size of wildfires within the boundaries of the hydrographic Great Basin have increased artificially over the past few decades in response to the range expansion of invasive annual grasses (that is, primarily cheatgrass native to Eurasia) and changes in land-management practices (Baker, 2006, 2011; Brooks and others, 2015; Ielmini and others, 2015). However, trends in burn frequency, wildfire size, and other attributes have been shown to vary substantially across the range of sage-grouse (Brooks and others, 2015). Within the Great Basin, wildfire is highly probable when cover of annual grass increases to values greater than 45 percent (Link and others, 2006; cited by Miller and others, 2011), and a large majority of sagebrush ecosystems within the Great Basin are at high risk of wildfire if cheatgrass expansion continues at its unfettered pace (Suring and others, 2005; cited by Miller and others, 2011). Importantly, evidence of the chronic effect suggests that the adverse impacts associated with wildfire on sage-grouse populations are primarily driven by replacement of sagebrush following fire to invasive grasses. These findings indicate that model-predicted increases in cumulative burned area (that is, wildfire-scars) over the next 30 years will have significant negative impacts on sage-grouse habitat and long-term sage-grouse population trajectory.

Given current rates of cumulative burned area within $5 \mathrm{~km}$ of leks, model-based projections indicate continued declines for sage-grouse in the Great Basin over the next three decades under most scenarios. Across all R\&R classes within the Great Basin, we projected a median of 44 percent (95-percent confidence limit; 22 to 69 percent) of current sage-grouse population numbers will remain by the mid-2040s. Our projections are similar to those of another recent study conducted across the four sage-grouse management zones within the Great Basin, which projected a 50-percent reduction (range 32-60 percent) in carrying capacity (a surrogate for population size) by 2043 (Garton and others, 2015). These consensus findings were reached despite distinctly different methodologies between these studies. For example, our study employed Bayesian inferences derived from individual lek complexes modeled with density-dependence, wildfire, and precipitation covariates while implementing random effects to account for random variation among site and year. Because these environmental conditions (that is, wildfire and precipitation) often change over time and can demonstrate cyclical patterns (Fedy and Doherty, 2011), our modeling approach allowed for temporal variation in rate of change as a function of short-term changes in those environmental factors over the past 30 years. In other words, our population rate of change was not constrained to fit a linear time trend. However, our 30-year projections were based on predicted average annual changes in cumulative burned area over time (that is, linear change) under different precipitation scenarios. In contrast, Garton and others (2015) applied maximum likelihood estimates derived from larger regional clusters of leks modeled with density-dependence and temporal (that is, year) effects, instead of environmental covariates. Year effects also can serve as a proxy for environmental conditions that change over time. Thus, similar projections among studies, coupled with exceptional fit of our model, indicate that wildfire and precipitation patterns explain temporal patterns in sage-grouse population size in the Great Basin. Although estimation of growth rate is sensitive to variation in absolute population size relative to carrying capacity and cyclic dynamics (May, 1974), similar conclusions reached by both studies indicate that estimated effects are not spurious artifacts of a specific modeling technique. 
Sage-grouse in the Great Basin essentially inhabit a cold desert where ecosystem productivity is tied strongly to water availability (Noy-Meir, 1973). It follows that periods of above-average precipitation result in food and cover resources that boost survival of young sage-grouse and contribute to population recruitment (Blomberg and others, 2012; Guttery and others, 2013). Precipitation supports moisture recharge of upland mesic sites where forbs and invertebrates become abundant as food for young grouse (Casazza and others, 2011). Thus, precipitation may provide a population-level buffer against subsequent periods of drought, where prolonged drought is likely to have deleterious impacts on population persistence, independent of wildfire. In our study, sage-grouse population growth responded positively to increases in total precipitation during spring, summer, and fall months, supporting grouse reproduction. However, this positive effect was counteracted as cumulative burned area in relation to leks increased across the Great Basin, and was nullified where burned areas were the largest. Blomberg and others (2012) found a similar pattern at a local study site located within central Nevada. Hence, wildfire acts to negate the positive effects of cyclically favorable weather on sage-grouse population growth and appears to do so across multiple spatial scales.

Our modeling approach has two informative and novel aspects. The first of which is our spatially explicit incorporation of different recovery times for sagebrush with range-wide concepts of resilience and resistance that are currently a cornerstone of sagebrush ecosystem management. Habitat in the low $R \& R$ comprises approximately 40 percent of all habitat with mapped $R \& R$ values in the Great Basin, and an ecosystem that is highly susceptible to cheatgrass invasion following disturbance. Accordingly, current R\&R-based management strategies call for protecting intact low R\&R habitat "of high conservation value" from wildfire, and enhancing R\&R in moderate and high R\&R habitats in the early stages of cheatgrass invasion where restoration success is high because, in part, of increasing cover of perennial grasses and forbs and reducing large-woody fuel loads such as encroaching pinyon-juniper (Chambers and others, 2014a, 2014b). Our model-simulated conversion of burned habitat with low R\&R to a permanent burn-scar integrates the rather high likelihood of a hysteretic transition to a cheatgrass-invaded state without intensive (and sometimes ineffective) management intervention. It follows that wildfire had the most substantial impact on sage-grouse inhabiting these habitats where projected population declines were greatest.

However, these R\&R based projections also predicted 30-year declines for sage-grouse inhabiting moderate and high R\&R habitats. Although moderate and high R\&R habitats may recover relatively quickly in ecological time and restoration of sagebrush ecosystems are thought to have a high likelihood of success (Chambers and others, 2014a, 2014b), our findings suggest that wildfires within these habitats still can be harmful to sage-grouse survival and recruitment, especially if wildfires increase in size and frequency. Hence, relatively fast ecosystem recovery times in moderate and high R\&R habitats under the current burn trends in the Great Basin may be asynchronous with sage-grouse demographic response to post-wildfire recovery of sagebrush. Management of wildfire in sagebrush from a perspective of plant-soil dynamics and disturbance regimes can benefit from a greater understanding of sage-grouse demographic responses to wildfire provided by our modeling.

The second informative and novel aspect of our approach stems from our example management scenarios, which simulated focused reductions in cumulative burned area near leks within sage-grouse 'core areas' across the Great Basin. These areas are most meaningful to sage-grouse based on response indices of habitat suitability and abundance (Doherty and others, 2015). For example, high resolution maps depicting habitat suitability for sage-grouse have been developed recently in Nevada and northeast California (Coates and others, 2014). Core areas calculated in this Nevada and California region overlap with approximately 20 percent of overall sage-grouse habitat (48 percent of high quality) but encompass about 90 percent of the males counted. It follows that targeted fire suppression in these core areas could 
help conserve large blocks of the 'best' areas for sage-grouse in the Great Basin. A straightforward calculation between males counted per hectare within core versus non-core areas, revealed an approximate 32.8 -fold increase $(3,180$ percent increase) in 'return' by focusing on core opposed to noncore areas, and a 4-fold increase (298 percent increase) in return compared to random area of sagegrouse. In our example scenarios, reducing cumulative burned area per year by 25 percent in core areas under current regimes of median precipitation slows, but does not halt, projected rates of overall sagegrouse decline based on the 50th percentile of the posterior distributions of model derived parameters. However, reducing this area by 75 percent in core area under the current median or below average precipitation regimes may result in locally stable sage-grouse populations.

Importantly, our analysis incorporated recovery times as a function of their corresponding $R \& R$ index values. Thus, reduction in cumulative burned area can be achieved through management actions aimed at fire suppression as well as those that accelerate sagebrush recovery. We recognize that federal wildfire managers have reported that 97 percent of fires burned less than 1,000 acres of area, which may have been the result of initial attack fire suppression activities, and less than 1 percent were greater than 10,000 acres (Havlina and others, 2015). Although additional modeling would help us achieve reliable estimates of suppression rates and, perhaps, understand relationships between fire suppression rates versus burned areas in the Great Basin, increased suppression could lead to a significant reduction in cumulative burned area if potentially large wildfires (that is, mega-wildfires) are suppressed before they grow to unmanageable sizes. Importantly, approximately 32 percent of the estimated sage-grouse population within core areas (based on the maximum of lek counts between 2009 and 2014) is comprised primarily of low R\&R habitat within $5 \mathrm{~km}$ of leks. Because these sites are highly susceptible to invasive grass following wildfire and, thus, permanent loss of sagebrush, management actions focused on suppression and protection should be most effective. However, it follows that core area leks surrounded by moderate or high R\&R may benefit from recovery actions, as well as suppression. This is important because sage-grouse core areas comprised 35 and 39 percent of high and moderate $R \& R$ classes, respectively. It is also important to recognize that the predicted 'success' of reducing cumulative burned area varies with amounts of precipitation. Although climate models predict future increases in winter precipitation in latitudes above $40^{\circ}$, the Great Basin as a whole is predicted to receive lower precipitation in upcoming years (Intergovernmental Panel on Climate Change, 2014; Schlaepfer and others, 2014). Thus, predicted outcomes of increasing sage-grouse populations with reductions of cumulative wildfire in core areas under high precipitation conditions will likely be most effective in northern areas where R\&R is relatively high and conditions generally are colder and wetter. However, reductions may be less effective in more southern areas of the Great Basin if climate model predictions hold.

Several caveats need to be considered when interpreting or implementing our results. First, recovery times specific to R\&R classes did not take implemented restoration efforts into account (for example, Emergency Stabilization and Rehabilitation; Pilliod and Welty, 2013). However, restoration success is highly variable (Arkle and others, 2014), and often dependent on local conditions (for example, wet sites with established perennial grasses) or intensity of restoration (for example, drill seeding) (Knutson and others, 2014). Thus, modeling restoration efficacy and success was beyond the scope of our Great Basin-wide analysis of wildfire effects on sage-grouse, but may contribute to additional variation in sage-grouse demographic response to wildfire. Similarly, post-wildfire recovery times for sagebrush can vary widely along elevation and precipitation gradients across the species' range. For example, Baker (2011) estimated that post-fire recovery times in mountain big sagebrush communities can take either fast (25-35 years) or slow (75-100 years) tracks for recovery. In contrast, recovery in arid Wyoming big sagebrush communities can be more prolonged (for example, 50-120 
years, Baker, 2006). The temporal duration of our time series (that is, 30 years) precluded testing of different recovery times to complete pre-wildfire conditions, so we focused on recovery times for minimal resources necessary (that is, 20 percent sagebrush return) to meet some sage-grouse life history requirements based on published estimates. Notably, our slower 'decelerated' recovery model showed less support from the data than the 'normal' recovery model. Collection of field-data to quantify a chronological sequence of wildfire-related vegetation change or recovery among $R \& R$ index classes could prove beneficial to these and other analyses, and is currently underway.

The second caveat is that our analysis did not parse the effects of prescribed fire versus wildfire, or potential beneficial effects of fire in sagebrush ecosystems. As stated previously in this report, most studies of fire effects on sage-grouse and their habitat have focused on prescribed fire. Connelly and others (2000a) described a significant decline in lek attendance following a prescribed fire that removed nearly 60 percent of existing sagebrush, while other studies have reported prescribed fire-related reductions in forage availability and quality (Nelle and others, 2000; Rhodes and others, 2010). However, low intensity prescribed fire followed by higher-than-normal annual precipitation has been associated with increased flowering and extended phenology of several forb taxa selected by sagegrouse and their chicks (Wrobleski and Kauffman, 2003). In addition, approximately 66 percent of sagegrouse leks tend to occur in sagebrush habitats with low to moderate R\&R that are being subjected to larger and more persistent wildfire scars according to our models. Yet, this pattern may not pertain to montane habitats at high elevation that our model did not specifically measure (Brooks and others, 2015), as well as other areas outside the Great Basin but within the range of sage-grouse with a preponderance of high R\&R habitats (for example, sage-grouse management zones I and II). Historical wildfire may have been beneficial in these wet and productive montane habitats where resilience is intrinsically high (Brooks and others, 2015). Suppression of wildfire at higher elevations also may have the unintended consequence of facilitating encroachment of pinyon-juniper woodlands across the Intermountain West (Miller and Rose, 1999; Miller and others, 2013), which decreases resilience to wildfire (Chambers and others, 2014a) and substantially reduces sage-grouse habitat suitability (Casazza and others, 2011; Baruch-Mordo and others, 2013).

Finally, several aspects of our empirical modeling and future projections incorporated 'best case' assumptions that require additional discussion of caveats. First, our 30-year projections began with stable populations $(\lambda=1.0)$ without explicit incorporation of modeled density-dependent or climatic parameter estimates. Rather, and for the sake of focusing on the primary question of interest (that is, fire), we drew from posterior distributions of parameter estimates for the effect of burned area that accounted for variation in density and precipitation. Second, we modeled and projected increases in cumulative burned area as a linear function with time (year). Notably, empirical data points for burned area near the end of the time-series fell outside the upper tail of the 95-percent prediction interval (fig. 10), which appears to take an exponential form. We chose to conservatively model a linear relationship owing to uncertainty in future rates of fire suppression and restoration efficacy. 
A third point that likely led to more optimistic predictions was our estimation of post-fire recovery rates for $R \& R$ index classes based on meta-analyses for mountain and Wyoming big sagebrush communities, where we assumed mountain big sagebrush comprised high and moderate R\&R, and Wyoming big sagebrush comprised low R\&R. Recovery for leks classified as high and moderate R\&R could be biased high if they also comprised some proportion of Wyoming big sagebrush. Moreover, our 'recovered' criteria of 20 percent return of pre-fire sagebrush cover only meets partial life history requirements, and may be too low to maintain adequate sage-grouse survival or recruitment. High sagebrush cover is not always associated with winter and brood rearing habitat, but large expanses of intact sagebrush often associates with high nesting success, and tall sagebrush is critical for providing forage in deep snow conditions (Connelly and others, 2000b; P. Coates and M. Casazza, U.S. Geological Survey, unpub. data, 2008).

We additionally defined burned area based on MTBS severity classes most indicative of vegetation change resulting from fire (that is, severity class $\geq 2$ ), yet MTBS severity classes are prone to errors of omission and commission. A recent analysis of MTBS fires within big sagebrush, black and low sagebrush, and grassland vegetation types across the range of the sage-grouse indicated that 70 percent of fires were classified using "initial assessment" imagery from the same growing season as the fire (typically a few months later) and the other 30 percent used "extended assessment" imagery from the first growing season after the fire (Brooks and others, 2015). In areas where the latter imagery is used, vegetation recovery prior to the imagery acquisition in the following growing season can result in lower dNBR values than if initial assessment imagery were used. Among all the 30-m MTBS pixels within the fires evaluated in Brooks and others (2015), initial assessment fires contained 13 percent fireseverity class 1 pixels, whereas extended assessment fires contained 35 percent fire-severity class 1 pixels. We do not know the specific proportions of initial versus extended assessment fires, and thus a potential underestimation of fire area is possible using the fires in this current study. However, by focusing on MTBS fires (that is, greater than 405 ha), we likely omitted approximately 5 percent of the total fire area that would have otherwise been represented by smaller fires (Eidenshink and others, 2007; Brooks and others, 2015). Thus, the absolute fire area values reported in the current study should be considered conservative underestimates. Departure from these 'best case' aforementioned assumptions or realization of caveats would likely lead to more rapid projected population declines and accentuated negative effects on sage-grouse.

Using large-scale datasets and well-founded R\&R concepts, our study identifies clear and predictable patterns of major sagebrush habitat loss associated with cumulative wildfire effects. R\&R concepts, which has often resulted in major losses of sagebrush habitat. Importantly, even under 'best case' assumptions, we demonstrate that adverse impacts associated with accelerating positive feedbacks between wildfire and invasive annual grass on sage-grouse populations are non-trivial in the Great Basin and, under some conditions, wildfire can nullify positive effects on sage-grouse that are normally associated with increased precipitation. Balancing management resources between post-wildfire restoration actions versus those of fire suppression is a challenging task facing land and wildlife agencies. Dependent on sagebrush ecosystem concepts and population responses of sage-grouse, our work provides an initial modeling framework and decision support tool to help land and wildlife managers sustain sage-grouse populations within the Great Basin. 


\section{References Cited}

Agrawal, A.A., Ackerly, D.D., Adler, F., Arnold, A.E., Caceres, C., Doak, D.F., Post, E., Hudson, P.J., Maron, J., Mooney, K.A., Power, M., Schemske, D., Stachowicz, J., Strauss, S. Turner, M.G., and Werner, E., 2007, Filling key gaps in population and community ecology: Frontiers in Ecology and the Environment, v. 5, p. 145-152.

Anthony, R.G., and Willis, M.J., 2009, Survival rates of female greater sage-grouse in autumn and winter in southeastern Oregon: Journal of Wildlife Management, v. 73, p. 538-545.

Arkle, R.S., Pilliod, D.S., Hanser, S.E., Brooks, M.L., Chambers, J.C., Grace, J.B., Knutson, K.C., Pyke, D.A., Welty, J.L., and Wirth, R.A., 2014, Quantifying restoration effectiveness using multiscale habitat models-Implications for sage-grouse in the Great Basin: Ecosphere, v. 5, issue 3, article 31.

Baker, W.L., 2006, Fire and restoration of sagebrush ecosystems: Wildlife Society Bulletin, v. 34, p. $177-185$.

Baker, W.L., 2011, Pre-Euro-American and recent fire in sagebrush ecosystems, in Knick, S.T., and Connelly, J.W., eds., Greater sage-grouse-Ecology and conservation of a landscape species and its habitats: Berkeley, University of California Press, p. 185-201.

Balch, J.K., Bradley, B.A., D'Antonio, C.M., and Gómez-Dans, J., 2013, Introduced annual grass increases regional fire activity across the arid western USA (1980-2009): Global Change Biology, v. 19, p. 173-183.

Baruch-Mordo, S., Evans, J.S., Severson, J.P., Naugle, D.E., Maestas, J.D., Kiesecker, J.M., Falkowski, M.J., Hagen, C.A., and Reese, K.P., 2013, Saving sage-grouse from the trees-A proactive solution to reducing a key threat to a candidate species: Biological Conservation, v. 167, p. 233-241.

Beisner, B.E., Haydon, D.T., and Cuddington, K., 2003, Alternative stable states in ecology: Frontiers in Ecology and the Environment, v. 1, p. 376-382.

Blomberg, E.J., Sedinger, J. S., Atamian, M. T., and Nonne, D.V., 2012, Characteristics of climate and landscape disturbance influence the dynamics of greater sage-grouse populations: Ecosphere, v. 3, issue 6, article 55.

Blomberg, E.J., Sedinger, J.S., Nonne, D.V., and Atamian M.T., 2013, Seasonal reproductive costs contribute to reduced survival of female greater sage-grouse: Journal of Avian Biology, v. 44, p. 149-158.

Brooks, M.L., Brown, C.S., Chambers, J.C., D'Antonio, C.M., Keeley, J.E., and Belnap, J., in press, Exotic annual Bromus invasions - Comparisons among species and ecoregions in the Western United States, in Germino, M.J., Chambers, J.C., and Brown, C.S., eds., Exotic brome grasses in arid and semi-arid ecosystems of the Western United States - Causes, consequences, and management implications: Springer Press.

Brooks, M.L., D'Antonio, C.M., Richardson, D.M., Grace, J.B., Keeley, J.E., DiTomaso, J.M., Hobbs, R.J., Pellant, M., and Pyke, D., 2004, Effects of invasive alien plants on fire regimes: Bioscience, v. 54, p. 677-688.

Brooks, M.L., Matchett, J.R., Shinneman, D.J., and Coates, P.S., 2015, Fire patterns in the range of greater sage-grouse, 1984-2013-Implications for conservation and management: U.S. Geological Survey Open-File Report 2015-1167, 66 p., http://dx.doi.org/10.3133/ofr20151167.

Brooks, M.L., and Pyke, D., 2001, Invasive plants and fire in the deserts of North America, in Galley, K., and Wilson, T., eds., Proceedings of the Invasive Species Workshop-The Role of Fire In the Control and Spread of Invasive Species. Fire Conference 2000-The First National Congress on Fire Ecology, Prevention, and Management, Miscellaneous Publications No. 11, Tall Timbers Research Station, Tallahassee, Florida, p. 1-14. 
Campbell, S.B., 2014, Soil temperature and moisture regime data for the range of greater sage-grouseData product: USDA Natural Resources Conservation Service, Portland, Oregon, Web site, https://www.sciencebase.gov/catalog/folder/537f8be5e4b021317a872flb?community=LC+MAP++ Landscape+Conservation+Management+and+Analysis+Portal.

Casazza, M.L., Coates, P.S., and Overton, C.T., 2011, Linking habitat selection and brood success in greater sage-grouse, in Sandercock, B.K., Martin, K., and Segelbacher, G., eds., Ecology, conservation, and management of grouse-Studies in avian biology (no. 39): Berkeley, University of California Press, p. 151-167.

Caswell, H., 2001, Matrix population models, second edition: Sunderland, Massachusetts, Sinauer Associates, p. 710.

Chambers, J.C., Bradley, B.A., Brown, C.S., D’Antonio, C., Germino, M.J., Grace, J.B., Hardegree, S.P., Miller, R.F., and Pyke, D.A., 2014a, Resilience to stress and disturbance, and resistance to Bromus tectorum L. invasion in cold desert shrublands of western North America: Ecosystems, v. 17, no. 2, p. 360-375.

Chambers, J.C., Pyke, D.A., Maestas, J.D., Pellant, M., Boyd, C.S., Campbell, S.B., Espinosa, S., Havlina, D.W., Mayer, K.E., and Wuenschel, A., 2014b, Using resistance and resilience concepts to reduce impacts of invasive annual grasses and altered fire regimes on the sagebrush ecosystem and greater sage-grouse - A strategic multi-scale approach: U.S. Department of Agriculture, Forest Service, Rocky Mountain Research Station, Fort Collins, Colorado, General Technical Report RMRSGTR-326, 73 p.

Chambers, J.C., Roundy, B.A., Blank, R.R., Meyer, S.E., and Whittaker, A., 2007, What makes Great Basin sagebrush ecosystems invasible by Bromus tectorum?: Ecological Monographs, v. 77, no. 1, p. 117-145.

Coates, P.S., Casazza, M.L., Blomberg, E.J., Gardner, S.C., Espinosa, S.P., Yee, J.L., Wiechman, L., and Halstead, B.J., 2013, Evaluating greater sage-grouse seasonal space use relative to leksImplications for surface use designations in sagebrush ecosystems: The Journal of Wildlife Management, v. 77, p. 1598-1609.

Coates, P.S., Casazza, M.L., Brussee, B.E., Ricca, M.A., Gustafson, K.B., Overton, C.T., SanchezChopitea, E., Mauch, K., Neill, L., Howe, K.B., Gardner, S.C., Espinosa, S.P., and Delehanty D.J., 2014, Spatially explicit modeling of greater sage-grouse (Centrocercus urophasianus) habitat in Nevada and northeastern California-A decision-support tool for management: U.S. Geological Survey Open-File Report 2014-1163, 84 p., http://dx.doi.org/10.3133/ofr20141163.

Connelly, J.W., Knick, S.T., Braun, C.E., Baker, W.L., Beever, E.A., Christiansen, T., Doherty, K.E., Garton, E.O., Hanser, S.E., Johnson, D.H., Leu, M., Miller, R.F., Naugle, D.E., Oyler-McCance, S.J., Pyke, D.A., Reese, K.P., Schroeder, M.A., Stiver, S.J., Walker, B.L., and Wisdom M.J., 2011, Conservation of greater sage-grouse - A synthesis of current trends and future management, in Knick S.T., and Connelly, J.W., eds., Greater sage-grouse - Ecology and conservation of a landscape species and its habitats: Berkeley, University of California Press, p. 549-563.

Connelly, J.W., Reese, K.P., Fischer, R.A., and Wakkinen, W.L., 2000a, Response of a sage grouse breeding population to fire in southeastern Idaho: Wildlife Society Bulletin, v. 28, p. 90-96.

Connelly, J.W., Schroeder, M.A., Sands, A.R., and Braun, C.E., 2000b, Guidelines to manage sage grouse populations and their habitats: Wildlife Society Bulletin, v. 28, p. 967-985.

Connelly, J.W., Reese, K.P., and Schroeder, M.A., 2003, Monitoring of greater sage-grouse habitats and populations: Station Bulletin 80, College of Natural Resources Experiment Station, Moscow, Idaho.

D'Antonio, C.M., and Vitousek, P.M., 1992, Biological invasions by exotic grasses, the grass/fire cycle, and global change: Annual Review of Ecology and Systematics, v. 23, p. 63-87. 
Daly, C., Halbleib, M., Smith, J.I., Gibson, W.P., Doggett, M.K., Taylor, G.H., Curtis, J., and Pasteris, P.P., 2008, Physiographically sensitive mapping of climatological temperature and precipitation across the conterminous United States: International Journal of Climatology, v. 28, p. 2031-2064.

Davis, D.M., and Crawford, J.A., 2014, Case study-Short-term response of greater sage-grouse habitats to wildfire in mountain big sagebrush communities: Wildlife Society Bulletin, v. 39, no. 1, p. 129-137.

Dennis, B., Ponciano, J.M., Lele, S.R., Taper, M.L., and Staples, D.F., 2006. Estimating density dependence, process noise, and observation error: Ecological Monographs, v. 76, p. 323-341.

Dennis, B., and Taper, M.L., 1994, Density dependence in time series observations of natural populations-Estimation and testing: Ecological Monographs, v. 64, p. 205-224.

Doherty, K.E., Evans, J.S., Coates, P.S., and Fedy, B.C., 2015, Importance of regional variation in conservation planning and defining thresholds for a declining species - A range-wide example of the greater sage-grouse: U.S. Fish and Wildlife Service, unpublished report.

Doherty, K.E., Naugle, D.E., Copeland, H.E., Pocewicz, A., and Kiesecker, J.M., 2011, Energy development and conservation tradeoffs-Systematic planning for greater sage-grouse in their eastern range, in Knick, S.T., and Connelly, J.W., eds., Greater sage-grouse: ecology and conservation of a landscape species and its habitats - Studies in avian biology: Berkeley, University of California Press, p. 505-516.

Doherty, K.E., Naugle, D.E., and Walker, B.L., 2010, Greater sage-grouse nesting habitat—The importance of managing at multiple scales: Journal of Wildlife Management, v. 74, p. 1544-1553.

Eidenshink, J., Schwind, B., Brewer, K., Zhu, Z.L., Quayle, B., and Howard, S., 2007, A project for monitoring trends in burn severity: Fire Ecology, v. 3, p. 3-22.

Evans, J.S., Murphy, M.A., Holden, Z.A., and Cushman, S.A., 2011, Modeling species distribution and change using random forests in predictive species and habitat modeling, in Drew, C.A. Wiersma, Y.F., and Huettmann, F., eds., Predictive species and habitat modeling in landscape ecologyConcepts and applications: New York, Springer.

Fedy, B.C., and Aldridge, C.L., 2011, The importance of within-year repeated counts and the influence of scale on long-term monitoring of sage-grouse: Journal of Wildlife Management, v. 75, p. 10221033.

Fedy, B.C., and Doherty, K.E., 2011, Population cycles are highly correlated over long time series and large spatial scales in two unrelated species-Greater sage-grouse and cottontail rabbits: Oecologia, v. 165, p. 915-924.

Fischer, R.A., Reese, K.P., and Connelly, J.W., 1996, An investigation on fire effects within xeric sage grouse brood habitat: Journal of Range Management, v. 49, p. 194-198.

Fischer, R.A., Wakkinen, W.L., Reese, K.P., and Connelly, J.W., 1997, Effects of prescribed fire on movements of female sage grouse from breeding to summer ranges, The Wilson Bulletin, v. 109, p. 82-91.

Garton, E.O., Connelly, J.W., Horne, J.S., Hagen, C.A., Moser, A.M., and Schroeder, M.A., 2011, Greater sage-grouse population dynamics and probability of persistence, in Knick, S.T., and Connelly, J.W., eds., Greater sage-grouse - Ecology and conservation of a landscape species and its habitatsStudies in avian biology: Berkeley, University of California Press, p. 293-381.

Garton, E.O., Wells, A.G., Baumgardt, J.A., and Connelly, J.W., 2015, Greater sage-grouse population dynamics and probability of persistence: Final Report to Pew Charitable Trusts, 90 p.

Gelman, A., Carlin, J.B., Stern, H.S., and Rubin, D.B., 2014, Bayesian data analysis. Second Edition. Chapman and Hall, 690 p. 
Gibson, R.M., 1996, A re-evaluation of hotspot settlement in lekking sage grouse; Animal Behaviour, v. 52, p. 93-1,005.

Gibson, R.M., and Langen, T.A., 1996, How do animals choose their mates?: Trends in Ecology and Evolution, v. 11, p. 468-470.

Gotelli, N.J., and Ellison, A.M., 2004, A Primer of Ecological Statistics, Sunderland, Massachusetts, Sinauer Associates Inc., p. 479.

Guttery, M.R., Dahlgren, D.K., Messmer, T.A., Connelly, J.W., Reese, K.P., Terletzky, P.A., Burkepile, N., and Koons, D.N., 2013, Effects of landscape-scale environmental variation on greater sage-grouse chick survival: PLoS ONE, v. 8, no. 6.

Halstead, B.J., Wylie, G.D., Coates, P.S., and Casazza, M.L., 2011, Bayesian adaptive survey protocols for resource management: The Journal of Wildlife Management, v. 75, p. 450-457.

Havlina, D.W., Anderson, P., Kurth, L., Mayer, K.E., Chambers, J.C., Boyd, C., Christiansen, T., Davis, D., Espinosa, S., Ielmini, M., Kemner, D., Maestas, J.D., Mealor, B., Pellant, M., Tague, J. and Vernon, J., 2015, Fire and fuels management contributions to sage-grouse conservation: a status report: Western Association of Fish and Wildlife Agencies. Unpublished Report. Cheyenne, Wyoming, accessed August 2015, at http://www.nifc.gov/fireandsagegrouse/docs/WAFWA_FireReport_v1.01.pdf.

Hobbs, R.J., Higgs, E., and Harris, J.A., 2009, Novel ecosystems-Implications for conservation and restoration: Trends in Ecology and Evolution, v. 24, p. 599-605.

Holloran, M.J., and Anderson, S.H., 2005, Spatial distribution of greater sage-grouse nests in relatively contiguous sagebrush habitats: The Condor, v. 107, p. 742-752.

Hooten, M.B., and Hobbs, N.T., 2014, A guide to Bayesian model selection for ecologists. Ecological Monographs, v. 85, p. 3-28.

Ielmini, M., Hopkins, T.E., Mayer, K.E., Goodwin, K., Boyd, C., Mealor, B., Pellant, M., and Christensen, T., 2015, Invasive plant management and greater sage-grouse conservation-A review and status report with strategic recommendations for improvement: Cheyenne, Wyoming, Western Association of Fish and Wildlife Agencies, 47 p.

Intergovernmental Panel on Climate Change, 2014. Intergovernmental panel on climate change. Climate change 2013 - The physical science basis - Contribution of Working Group I to the Fifth Assessment Report of the Intergovernmental Panel on Climate Change: Cambridge, United Kingdom and New York, New York, Cambridge University Press, 1,535 p.

Kéry, M., 2010, Introduction to WinBUGS for ecologists-Bayesian approach to regression, ANOVA, mixed models and related analyses: Academic Press, $320 \mathrm{p}$.

Knick, S.T., and Connelly, J.W., eds., 2011, Greater sage-grouse-Ecology and conservation of a landscape species and its habitats - Studies in avian biology (no. 38): Berkeley, University of California Press, 664 p.

Knutson, K.C., Pyke, D.A., Wirth, T.A., Arkle, R.S., Pilliod, D.S., Brooks, M.L., Chambers, J.C., and Grace, J.B., 2014, Long-term effects of seeding after wildfire on vegetation in Great Basin shrubland ecosystems: Journal of Applied Ecology, v. 51, p. 1,414-1,424.

Küchler, A.W., 1970, The potential natural vegetation of the conterminous United States-The National Atlas of the United States of America: Washington, D.C., U.S. Geological Survey.

Link, S.O., Keeler, C.W., Hill, R.W., and Hagen, E., 2006, Bromus tectorum cover mapping and fire risk: International Journal of Wildland Fire, v. 15, p. 113-119.

Manier, D.J., Bowen, Z.H., Brooks, M.L., Casazza, M.L., Coates, P.S., Deibert, P.A., Hanser, S.E., and Johnson, D.H., 2014, Conservation buffer distance estimates for greater sage-grouse-A review: U.S. Geological Survey Open-File Report 2014-1239, 14 p., http://dx.doi.org/10.3133/ofr20141239. 
May, R.M., 1974, Biological populations with nonoverlapping generations-Stable points, stable cycles, and chaos: Science, v. 186, p. 645-647.

Miller, R.F., Chambers, J.C., Pyke, D.A., Pierson, F.B.,and Williams, C.J., 2013, A review of fire effects on vegetation and soils in the Great Basin Region-Response and ecological site characteristics. U.S. Department of Agriculture, Forest Service, Rocky Mountain Research Station, Fort Collins, Colorado, General Techchnical Report RMRS-GTR-308, 126 p.

Miller, R.F., Knick, S.T., Pyke, D.A., Meinke, C.W., Hanser, S.E., Wisdom, M.J., and Hild, A.L., 2011, Characteristics of sagebrush habitats and limittions to long-term conservation, in Knick, S.T., and Connelly, J.W., eds., Greater sage-grouse-Ecology and conservation of a landscape species and its habitats - Studies in avian biology: Berkeley, University of California Press, p. 145-184.

Miller, R.F., and Rose, J.A., 1999, Fire history and western juniper encroachment in sagebrush steppe: Journal of Range Management, v. 52, p. 550-559.

Nelle, P.J., Reese, K.P., and Connelly, J.W., 2000, Long-term effects of fire on sage-grouse habitat: Journal of Range Management, v. 53, p. 586-591.

Nelson, Z.J., Weisberg, P.J. and Kitchen, S.G., 2014, Influence of climate and environment on post-fire recovery of mountain big sagebrush: International Journal of Wildland Fire, v. 23, p. 131-142.

Noy-Meir, I., 1973, Desert ecosystems-Environment and producers: Annual Review of Ecology and Systematics, v. 4, p. 25-51.

Pedersen, E.K., Connelly, J.W., Hendrickson, J.R., and Grant, W.E., 2003, Effect of sheep grazing and fire on sage grouse populations in southeastern Idaho: Ecological Modelling, v. 165, p. 23-47.

Pilliod, D.S., and Welty, J.L., 2013, Land treatment digital library: U.S. Geological Survey Data Series 806, http://dx.doi.org/10.3133/ds806.

Plummer, M., Stukalov, A., and Denwood, M., 2015, Bayesian graphical Mmdels using MCMC. R package 'rjags', version 3-15: The Comprehensive R Archive Network Web site, http://cran.rproject.org/web/packages/rjags/rjags.pdf.

R-Core-Team, 2014, R-A language and environment for statisticalcomputing: Vienna, Austria, $\mathrm{R}$ Foundation for Statistical Computing Web site, http://www.R-project.org/.

Rhodes, E.C., Bates, J.D. Sharp, R.N. and Davies, K.W., 2010, Fire effects on cover and dietary resources of sage-grouse habitat: Journal of Wildlife Management, v. 74, p. 755-764.

Rowland, M.M., Wisdom, M.J., Suring, L.H., and Meinke, C.W., 2006, Greater sage-grouse as an umbrella species for sagebrush-associated vertebrates: Biological Conservation, v. 129, p. 323-335.

Scheffer, M., Carpenter, S., Foley, J.A., Folke, C., and Walker, B., 2001, Catastrophic shifts in ecosystems: Nature, v. 413, p. 591-596.

Schlaepfer, D.R., Lauenroth, W.K., and Bradford, J.B., 2014, Natural regeneration processes in big sagebrush (Artemisia tridentata): Rangeland Ecology and Management, v. 67, p. 344-357.

Schroeder, M.A., Aldridge, C.L., Apa, A.D., Bohne, J.R., Braun, C.E., Bunnell, S.D., Connelly, J.W., Deibert, P.A., Gardner, S.C., Hilliard, M.A., Kobriger, G.D., McAdam, S.M., McCarthy, C.W., McCarthy, J.J., Mitchell, D.L., Rickerson, E.V., and Stiver, S.J., 2004, Distribution of sage-grouse in North America: Condor, v. 106, p. 363-376. 
Schroeder, M.A., and White, G.C., 1993, Dispersion of greater prairie chicken nests in relation to lek location-Evaluation of the hot-spot hypothesis of lek evolution: Behavioral Ecology, v. 4, p. 266-270.

Seastedt, T.R., Hobbs, R.J., and Suding, K.N., 2008, Management of novel ecosystems-Are novel approaches required?: Frontiers in Ecology and the Environment, v. 6, p. 547-553.

Standish, R.J., Hobbs, R.J., Mayfield, M.M., Bestelmeyer, B.T., Suding, K.N., Battaglia, L.L., Eviner, V., Hawkes, C.V.,Temperton, V.M., Cramer, V.A., Harris, J.A., Funk, J.L., and Thomas, P.A., 2014, Resilience in ecology-Abstraction, distraction, or where the action is?: Biological Conservation, v. 177, p. 43-51.

Stephens, P.A., Pettorelli, N., Barlow, J., Whittingham, M.J., and Cadotte, M.W., 2015, Management by proxy?-The use of indices in applied ecology: Journal of Applied Ecology, v. 52, p. 1-6.

Suding, K.N., Gross, K.L., and Houseman, G.R., 2004, Alternative states and positive feedbacks in restoration ecology: Trends in Ecology and Evolution, v. 19, p. 46-53.

Suring, L.H., Wisdom, M.J., Tausch, R.J., Miller, R.F., Rowland, M.M., Schueck, L., and Meinke, C.W., 2005, Modeling threats to sagebrush and other shrubland commmunities, in Wisdom, M.J., Rowland, M.M., and Suring, L.H., eds., Habitat threats in the sagebrush ecosystem-Methods of regional assessment and applications in the Great Basin: Lawrence, Kansas, Aliance Communications Group, p. 114-149.

U.S. Department of the Interior, 2015, Secretarial Order No. 3336 - Rangeland Fire Prevention, Management, and Restoration, accessed August 2015, at http://www.fws.gov/greatersagegrouse/documents/Threats/20150106DOI-Fire-Order.pdf.

U.S. Fish and Wildlife, 2010, Endangered and threatened wildlife and plants; 12-month findings for petitions to list the greater sage-grouse (Centrocercus urophasianus) as threatened or endangered: Federal Register, v. 75, no. 55, p. 13909-14014, accessed July 2015, at https:/www.federalregister.gov/articles/2010/03/23/2010-5132/endangered-and-threatened-wildlifeand-plants-12-month-findings-for-petitions-to-list-the-greater.

Vander Wal, E., and Rodgers, A.R., 2012, An individual-based quantitative approach for delineating core areas of animal space use: Ecological Modelling, v. 224, p. 48-53.

Western Association of Fish and Wildlife Agencies, 2015. Greater sage-grouse population trends: an analysis of lek count databases 1965-2015, accessed August 2015, at http://www.wafwa.org/Documents\%20and\%20Settings/37/Site\%20Documents/News/Lek\%20Trend \%20Analysis\%20final\%208-14-15.pdf.

Wrobleski, D.W., and Kauffman, J.B., 2003, Initial effects of prescribed fire on morphology, abundance, and phenology of forbs in big sagebrush communities in southeastern Oregon: Restoration Ecology, v. 11, p. 82-90.

Zar, J.H., 1996, Biostatistical analysis (3rd ed.): Upper Saddle River, New Jersey, Prentice Hall. 
Publishing support provided by the U.S. Geological Survey

Science Publishing Network, Tacoma Publishing Service Center

For more information concerning the research in this report, contact the Director, Western Ecological Research Center

U.S. Geological Survey

3020 State University Drive East

Sacramento, California 95819

http://werc.usgs.gov/ 
